Maria Montoro

\section{El arquitecto como educador de la sociedad}

\author{
El monumento a Federico II entre los años 1787 y 1797
}

\author{
Palabras clave: educación, regeneración, monumento, filósofo, proceso.
}

El concurso para el monumento a Federico II fue convocado por primera vez el 25 de enero de 1787, en un momento marcado por la profunda crisis que a todos los niveles atravesaba el Sacro Imperio Romano Germánico. La necesidad de revertir la mala situación existente hizo que una parte importante de la intelectualidad alemana apuntase a la educación como único medio de regeneración posible. En este sentido, un buen número de propuestas escultóricas relacionaban al monarca con la figura del filósofo. Por su parte, los proyectos presentados por Hans Christian Genelli, Carl Gotthard Langhans, Heinrich Gentz y Friedrich Gilly, desarrollaban diversas estrategias utilizando la arquitectura como medio para producir una mejora en la vida del hombre, desde el mero embellecimiento estético planteado por Langhans, pasando por la capacidad de abstracción de la belleza reivindicada por Gentz, hasta el edificio educativo proyectado por Gilly quien, con su propuesta para el monumento, construye un mecanismo capaz de transformar al gobernante en filósofo.

\section{Un puente entre dos crisis}

$E^{\mathrm{n}}$ n las últimas décadas del siglo XVIII las obsoletas estructuras politicas y económicas del Sacro Imperio Romano Germánico se tambaleaban de forma preocupante, anunciando un derrumbe que parecía inevitable. Paralelamente a las labores de apuntalamiento que las autoridades germanas llevaban a cabo, en forma de tímidas reformas, se abrió un debate entre las capas intelectuales de la población para tratar de definir cuál habría de ser el rumbo que en lo sucesivo tomara Alemania como país.

En el clima de relación con la antigüedad que caracterizó a la segunda mitad del siglo XVIII, una parte importante de la intelectualidad alemana identificó el desequilibrio existencial que el desmoronamiento del Imperio suponía, con otra de las grandes crisis vivida por el mundo civilizado cuando, allá por el 404 a.C., la derrota definitiva de Atenas en las guerras del Peloponeso acabase con la democracia ateniense, instaurando el régimen de los 30 tiranos. Se podría decir que los germanos de finales del XVIII, o al menos algunos de ellos, tendieron un puente hasta el ocaso del siglo V a.C. y trataron de trasladar algunas de las recetas anticrisis que surgieron en aquel momento hasta sus dias. En este sentido, una de las influencias más importantes llegó de la mano de Sócrates, el gran moralizador de la historia en palabras de Francisco Rodríguez Adrados (2003). Sócrates fue el primero, según el citado autor, que trató de producir una moralización de la política, al conciliar la moral personal con la pública. La concepción socrática de la moral implica la unificación de las competencias personales con un ideal de conducta que obedece a una ley interna, asociada a su vez a la virtud.

Frente a los grupos aristocráticos conservadores, que defendian el carácter hereditario de toda bondad, Sócrates sostiene que la virtud puede y debe ser enseñada. A partir de aquí, su ideal de Estado se construye sobre un ideal educativo puesto que, para él, la función primordial de un gobernante es ayudar al ciudadano a desarrollar su propia ley interna.

Platón recogió el principio moralizante de Sócrates y lo desarrolló hasta darle una forma concreta al crear su Estado ideal o República, a la cabeza de la cual sitúa a una élite intelectual, "los guardianes"; éstos habrian recibido una educación especifica, orientada fundamentalmente a la observación de las normas de conducta (Platón 1988: 376).

En la Alemania deprimida del último tercio del siglo XVIII, la necesidad de revertir la mala situación que de forma generalizada se hacía extensiva a todos los ámbitos se tradujo en una apuesta decidida por la educación como único instrumento de rehabilitación posible. La preocupación por el aspecto formativo durante estos años fue tal, que provocó la publicación de más escritos sobre educación que en los trescientos años precedentes, como apun- 
Figura 1: Vista exterior de la propuesta enviada a concurso por Hans Christian Genelli y Johann Gottfried Schadow, 1787 (Oncken, 1981, 23a).
Figura 2: Alzado de los propileos de Atenas (Stuart y Revett 1787: lámina III).

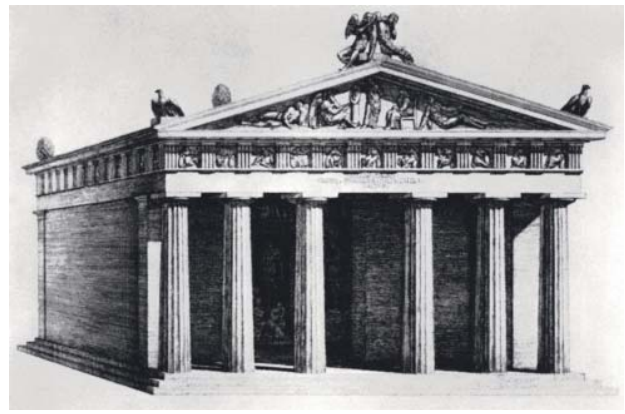

ta Clemens Menze (1975: 11). Entre los pensadores alemanes del momento más comprometidos con las cuestiones pedagógicas se encuentra Immanuel Kant, quien instaba a los Estados a abandonar sus planes expansionistas para centrarse en la labor de formar internamente a sus ciudadanos (Cassirer 2007: 186).

En este contexto de fervor educativo se convocó el concurso para el monumento a Federico II, que fue interpretado como una llamada a definir las líneas generales en que se encuadraria en lo sucesivo el arte oficial de Alemania, a la vez que definía un marco propicio para la discusión sobre el papel pedagógico de la arquitectura, en tanto que instrumento al servicio de la regeneración política.

\section{El templo a la razón de Genelli y Scha- dow}

El concurso fue convocado por primera vez el 25 de enero de 1787. Poco después, el arquitecto Hans Christian Genelli (17631823) y el escultor Johann Gottfried Schadow (1764- 1850) enviaban desde Roma una propuesta conjunta: un templo próstilo que alojaba en su interior una escultura del monarca.

Según Alste Oncken (1981: 43), ésta es la primera vez que se utilizaba un templo griego como base para la realización de un mausoleo, no sólo en Berlín, sino en todo el territorio alemán.

La propuesta incluía una vista en perspectiva del objeto (figura 1), del cual se mostraban dos de las fachadas: la de acceso y una de las laterales. En cuanto a la prime$\mathrm{ra}$, se trata de un frente con seis columnas dóricas acanaladas que sujetan un arquitrabe. Sobre éste, la tradicional disposición de friso con alternancia de triglifos y metopas, cornisa y frontón.

La fachada lateral es un muro ciego, tratado como un paramento continuo y homogéneo. Las esquinas de la cella se refuerzan mediante la utilización de pilastras; la inclusión de este elemento constructivo rebate la teoria de Marc- Antoine Laugier, quien en el Essai sur l'architecture (17551), vigente aún en Alemania en 1787 según Klaus Jan Philipp (1997: 102), consideraba abyecto su uso, al entender que no habían derivado de la naturaleza. En este caso, Genelli reivindica su utilización, haciendo suya la teoría según la cual, las pilastras no son el resultado de una degeneración de las columnas, sino un tipo de estructura propio, derivado de los muros originales de la cella del templo griego.

Las columnas de la fachada de acceso están situadas de manera no homogénea, puesto que el intercolumnio central es más ancho que los restantes. Este peculiar gesto relaciona el templo de Genelli y Schadow con otra fachada clásica, la construida por Mnesicles en el 437 a. C. en los propíleos de la acrópolis de Atenas. La fachada de Mnesicles es un elemento puramente frontal, que adolece del componente escultórico de otros edificios del recinto sagrado ateniense, puesto que no está concebido para ser rodeado, sino para ser atravesado de forma perpendicular. El hecho de que la dimensión de los intercolumnios sea variable, matizando el hueco

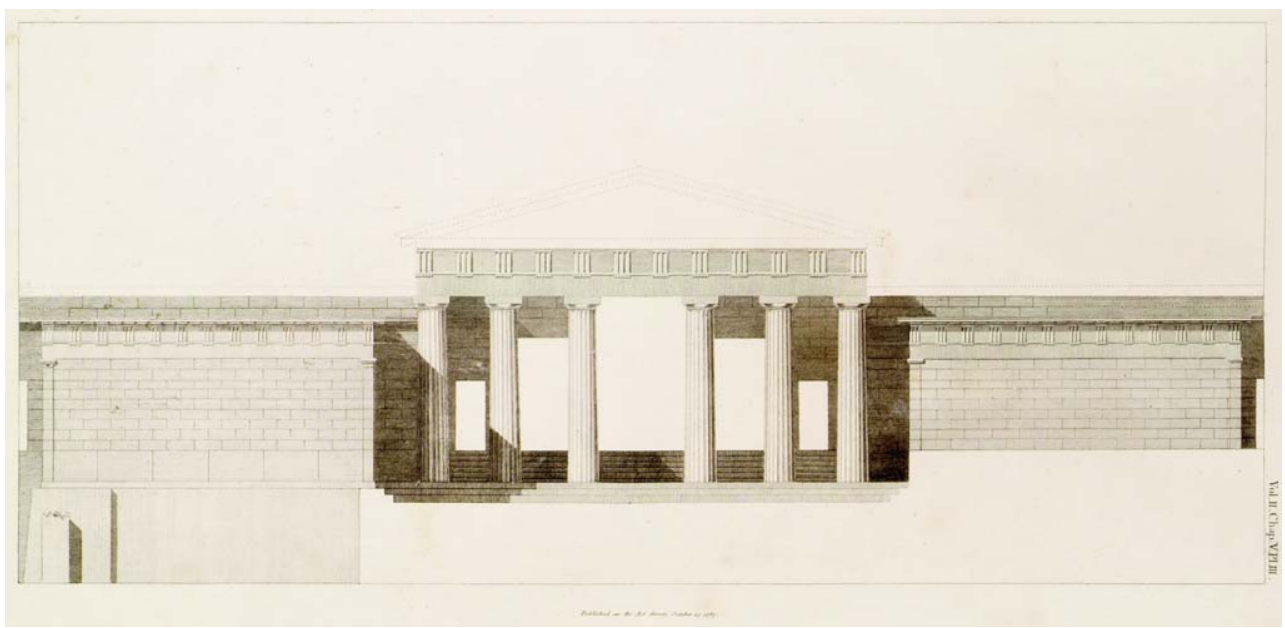


central con una distancia mayor, potencia la frontalidad del conjunto, resaltando el valor del paño como elemento de entrada. El fragmento de los propíleos que Genelli reproduce es una fachada en el más puro sentido de la palabra.

Por otra parte, 1787 es también el año de la publicación del segundo volumen de The Antiquities of Athens, de James Stuart y

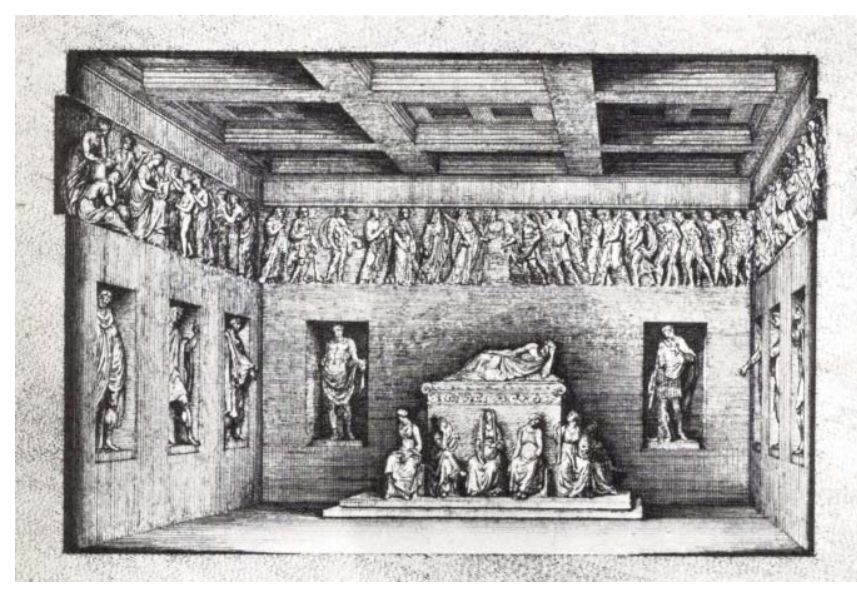

Figura 3: Interior de la propuesta enviada por Genelli y Schadow (von Simson 1975: página sin determinar).

Figura 4. Grupo escultórico realizado por Johann Gottfried Schadow para el monumento a Federico II, 1787 (Arenhövel 1979: 202).
Nicholas Revett, en el que éstos realizaban una profusa reproducción del monumento ateniense. El debate en torno a los propíleos fue una constante durante los últimos años del siglo XVIII en el país germano ${ }^{2}$; si bien es cierto que la obra de Stuart y Revett pudo alimentar la discusión, el valor simbólico del monumento, en tanto que puerta de entrada a un universo cultural, se situaba en el centro de la reflexión sobre el papel que la cultura debía desempeñar en lo sucesivo en Alemania.

Ambos monumentos, las portadas de acceso a la Acrópolis y el templo de Genelli, definen un itinerario, pero en el ejemplo ateniense, el recorrido conduce a un recinto al aire libre mientras que, en el monumento berlinés, el camino termina dentro del propio edificio (figura 3).

El interior del templo es un espacio cerrado, al fondo del cual se encuentra el grupo escultórico diseñado por Schadow: un basamento de piedra sobre el que yace Federico en forma de figura meditativa, ataviada con una toga que apenas cubre su cuerpo desnudo (figura 4). A los pies del paralelepipedo que sirve de lecho al monarca se encuentran las nueve musas; situar a las musas alrededor del basamento sobre el que descansa la figura yacente convierte el pedestal en el monte Olimpo, y equipara a Federico con Zeus, el rey de todos los dioses. En la tablilla que porta una de las divinidades puede leerse "Filo- sof de Sanssouci" (Arenhövel 1979: 202). De este modo, Schadow recoge dos atribuciones fundamentales en la figura del monarca prusiano: el escalón más alto en la jerarquía de las antiguas divinidades, al equipararlo con Zeus, y la condición de pensador.

La luz procede del exterior y penetra en la estancia a través del hueco de acceso, reflejándose en el suelo, que queda convertido así en fuente luminosa a partir de la cual se deducen las sombras principales, a saber, la que el grupo escultórico arroja tras de sí, contribuyendo a delimitar su perfil, y aquellas que las vigas centrales del techo producen en los laterales, reforzando el eje de acceso. La iluminación, aparte de estos matices, es homogénea en el resto de la estancia, es decir, se trata de una luz descriptiva que contribuye a explicar formalmente el proyecto, pero que no se corresponde con la claridad real que tendría la escena; es una luz que ha sido racionalizada.

Además del plano del suelo, la representación se construye a partir de tres superficies verticales y una horizontal, que cierra la estancia por la parte superior. El muro que contiene el hueco de acceso ha sido eliminado en su totalidad, permitiendo así una vista completa del espacio interior. La cara interna de los muros ha recibido el mismo tratamiento homogéneo en su superficie que los paños exteriores; en ellos se han horadado nichos rectangulares que acogen esculturas ataviadas con ropajes antiquizantes.

Estas figuras se encuentran en un nivel superior al de las musas, por lo que se deduce que son la representación de los dioses del Olimpo. En el dibujo presentado por Genelli y Schadow, sin embargo, sólo observamos ocho de estas figuras; añadiendo la del propio Federico, que encarna la figura de Zeus, sumarian un total de nueve, por lo que faltarian tres más para completar el grupo de las doce deidades que habitaban el monte sagrado. Éstas

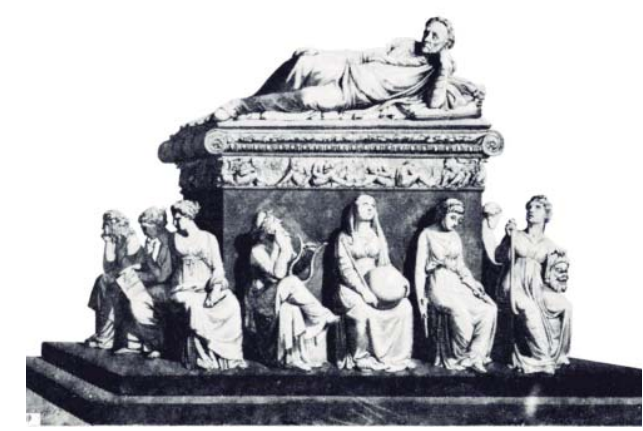


Figura 5. Planta del palacio y templo de Salomón según Leonhard Christoph Sturm (Behr 1990: 115). debian encontrarse, lógicamente, en la cara interior del muro de acceso, que ha sido retirado por cuestiones derivadas de la representación. Sobre esta superficie, sin embargo, sólo sería posible ubicar dos nichos más, uno a cada lado de la puerta de entrada, por lo que la figura restante tendría que ser necesariamente el propio visitante, elevado a la categoría de dios olimpico al atravesar el hueco de acceso.

En la parte superior de los muros interiores, sobre los nichos que acogen las figuras de los dioses, se ha dispuesto un friso decorativo que, a modo de banda rehundida, unifica la estancia. Este elemento recuerda al friso que recorría la cella del Partenón pero, a diferencia de aquel, éste se encuentra en la cara interna del muro, lo que produce una transformación del interior en exterior, de lo cóncavo en convexo. Apenas unos centímetros sobre él, apoyado sobre el límite superior de los muros de cerramiento, se encuentra el plano del techo: una estructura reticular formada por potentes vigas que, al cruzarse, determinan nueve campos cuadrangulares intermedios.

Partiendo de la propia concepción del interior del templo, convertido a su vez en exterior por la inversión que en el carácter de los muros ha realizado el friso, y teniendo en cuenta que se trata de una recreación del Olimpo de los dioses, el elemento elegido para limitarlo verticalmente no puede ser otro que el propio cielo, o un objeto celestial con una carga simbólica equivalente.

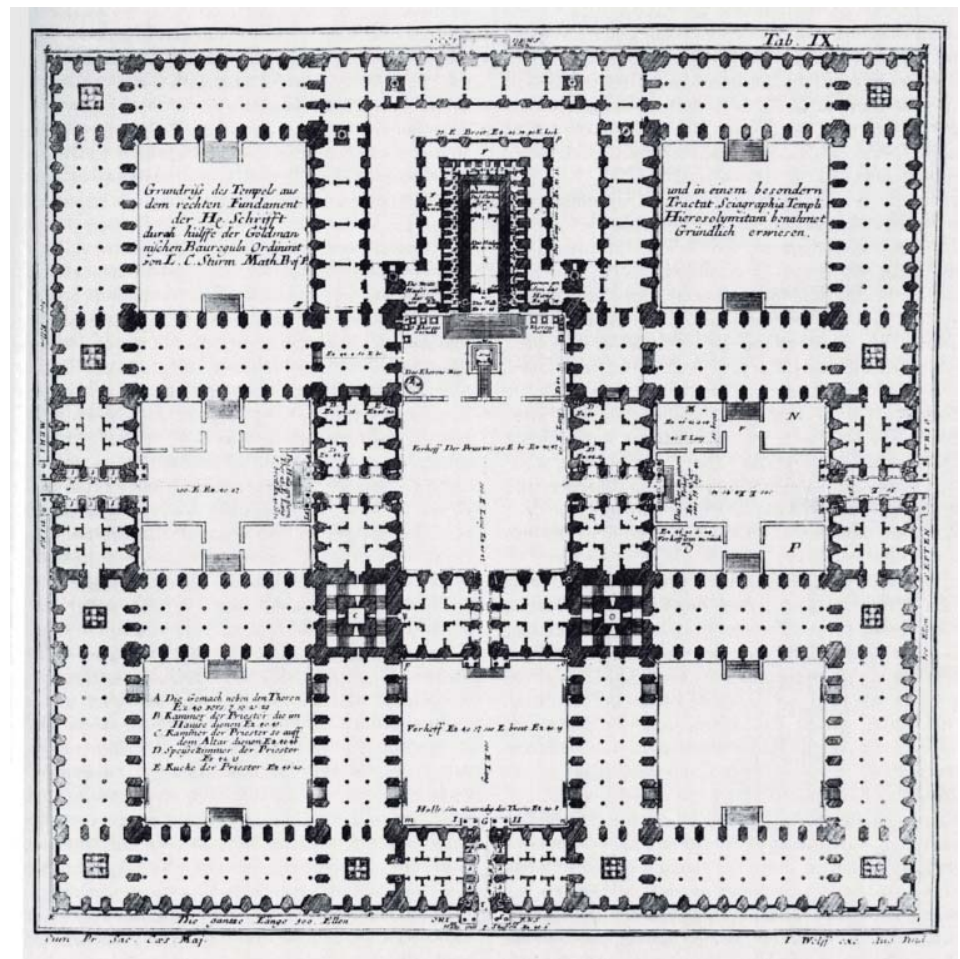

Es éste un cielo extraño, en cualquier caso, puesto que no permite la entrada de la luz. Sin embargo, en el libro del Apocalipsis se describe uno parecido:

"Y las doce puertas eran doce perlas, en cada una, una; cada puerta era de una perla. Y la plaza de la ciudad era de oro puro, como vidrio resplandeciente.

Y no vi en ella templo; porque el Señor Dios Todopoderoso es el templo de ella, y el Cordero.

Y la ciudad no tenía necesidad de sol ni de luna para que resplandezcan en ella: porque la claridad de Dios la iluminó, y el Cordero es su lumbrera." (Apocalipsis 21, 21- 23, De Valera 1863)

Es dios, por lo tanto, quien ilumina la escena; el dios de todos los dioses paganos en el Olimpo alemán de finales del siglo XVIII, es decir, la razón. Una razón que Genelli materializa recurriendo al trabajo de Leonhard Christoph Sturm, el primer arquitecto alemán que trató de sintetizar la Mathesis Universalis en una teoría de la arquitectura concreta, basada en principios matemáticos. Para la puesta en práctica de las demandas de Sturm era necesario proporcionar una formación científica a los arquitectos. Esto suponía, como indica Christian Schädlich (Behr 1990: 114), una modificación en la consideración del trabajo del arquitecto, que pasaba de ser un simple artesano a supervisor, tanto de la parte técnica, como de la artística, algo que ya se había producido en Italia desde el siglo XV. Esta situación era la responsable, según Schädlich, de la superioridad teórica de los arquitectos italianos frente a los alemanes, que no habian conseguido aún recomponerse tras la fuerte desubicación que la guerra de los Treinta Años (1618- 1648) había supuesto.

Como indica Robert Jan van Pelt (Ramírez, et al. 1994: 120-121), en Alemania, en el periodo que siguió a este conflicto bélico, los teóricos de la arquitectura acabaron apartándose definitivamente de los razonamientos que regian en Italia y Francia, basados en la intemporalidad de los órdenes clásicos, y se centraron en la historia de la arquitectura, llegando de este modo al descubrimiento del templo de Jerusalén, un edificio que había existido y que había dejado de existir. Según van Pelt, en la Alemania arruinada tras la guerra de los Treinta Años, el templo de Salomón representaba la promesa implícita de la arquitectura como instrumento de salvación.

Muy influenciado por la obra de Nicolaus Goldmann, Sturm desarrolló una teoría 
Figura 6: Propuesta de Schadow, 1796 (von Simson 1975: página sin especificar).

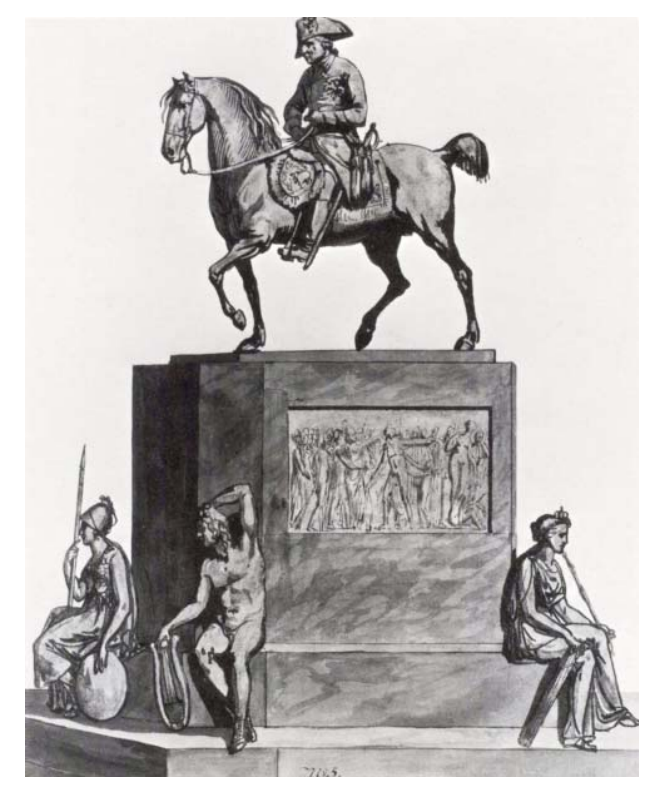

estética en la que sitúa el templo hierosolimitano en el origen de la arquitectura. Sturm afirma que todos los elementos, los medios y las posibilidades constructivas son observadas en este edificio, la obra más excelsa de la construcción sagrada. El templo de Salomón se convierte para Sturm en fundamento de la arquitectura, la quintaesencia de la forma constructiva perfecta.

El techo del proyecto presentado por Genelli para el monumento a Federico II (figura 5) puede considerarse como una abstracción de la planta del templo de Salomón que Sturm dibujó siguiendo la pauta de Goldmann quien, a su vez, había obtenido su modelo de una simplificación de la propuesta de Villalpando, como indica van Pelt (Ramírez et al. 1994: 122).

Al incluir la planta del templo de Salomón en su propuesta, Genelli refiere a otro origen de la arquitectura, no al que representan los propíleos atenienses emulados en
Figura 7. Esquema de la autora sobre propuesta de Schadow, 1796 (von Simson 1975: página sin especificar).

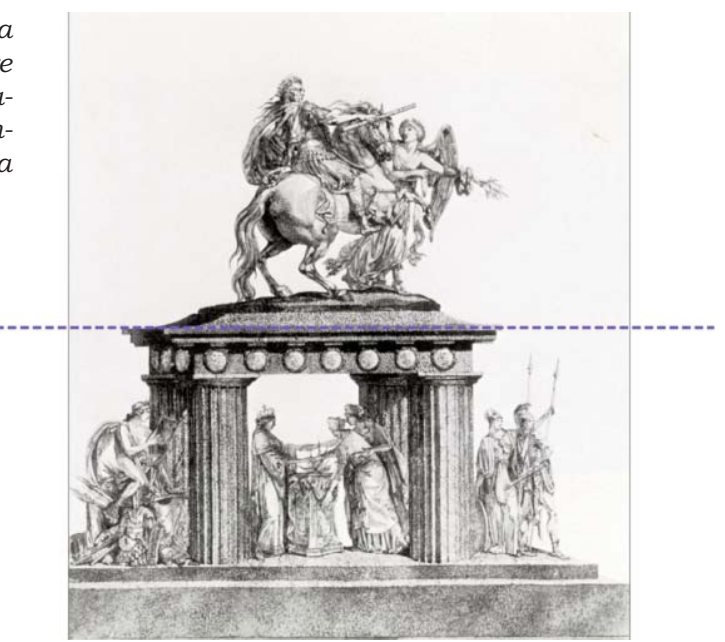

la fachada de acceso, sino a aquél al que apuntaba la más reciente tradición alemana. Y así, unificando estas dos corrientes en torno a la figura de Federico II, Genelli define su idea de estado cultural como un compendio de las principales teorías arquitectónicas del momento.

\section{El rey filósofo}

La trayectoria del concurso fue larga y accidentada, prolongándose durante más de sesenta años, hasta culminar en 1851 con la instalación de la escultura ecuestre de Christian Daniel Rauch (1777- 1857) en la Unter den Linden.

La heterogeneidad de las propuestas recibidas evidencia la falta de directrices comunes, no ya entre los distintos autores, sino incluso dentro de los proyectos enviados por un mismo artista. De 1796 datan estos dos grupos ecuestres remitidos por Schadow. En uno de ellos aparece Federico a caballo, vistiendo uniforme prusiano ${ }^{3}$ (figura 6); jinete y caballo se alzan sobre un pedestal de afiladas aristas, al pie del cual se hallan Atenea, Apolo y Artemisa en posición de descanso. En uno de los laterales mayores de la base se ha representado, mediante la realización de un bajorrelieve, al monarca en medio de una escena mitológica. La sobriedad del basamento transmite la solemnidad de los objetos fúnebres.

La otra propuesta es totalmente diferente (figura 7); en esta ocasión, la piedra monolitica del basamento ha sido sustituida por un templete de robustas columnas cilindricas acanaladas, bajo el cual la reina realiza un ritual acompañada de otras dos damas. La escena se encuentra flanqueada al exterior por figuras mitológicas; a la derecha Atenea y Ares, en posición erguida, y a la izquierda Apolo, tocando su lira sentado sobre un cúmulo de armas apiladas; escenas que refieren a la guerra y a la paz respectivamente. En la parte superior, la imagen épica de un Federico cuyo caba1lo encabritado es guiado por un ángel. En este caso el basamento adquiere protagonismo, al cobrar corporeidad imágenes que antes aparecian simplemente como un bajorrelieve; de este modo, el peso del conjunto se divide por igual en las dos partes: la inferior, que refiere al ámbito de actuación del monarca, es decir, a su memoria dentro del plano terrenal, y la superior, dedicada al propio personaje, idealizado y elevado a la categoría de héroe trágico. En esta propuesta, la figura superior ha perdido la solemnidad y la templanza en favor del ensalzamiento de la pasión, el exceso, la hybris. 

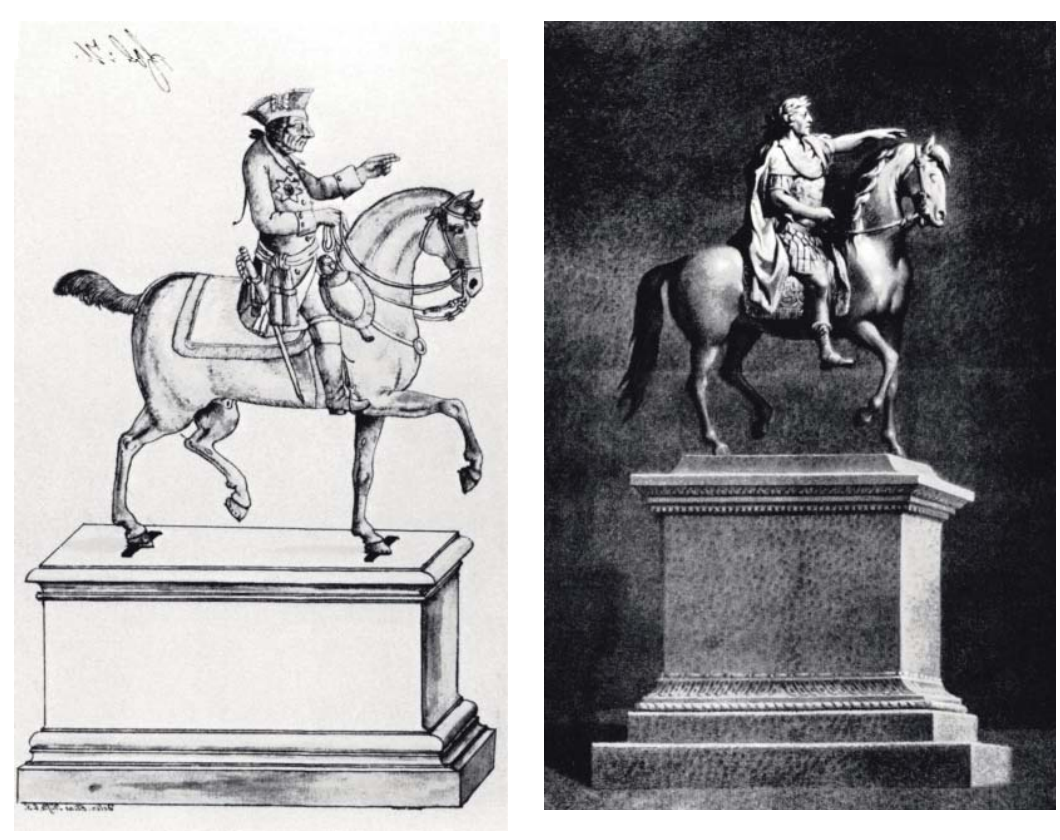

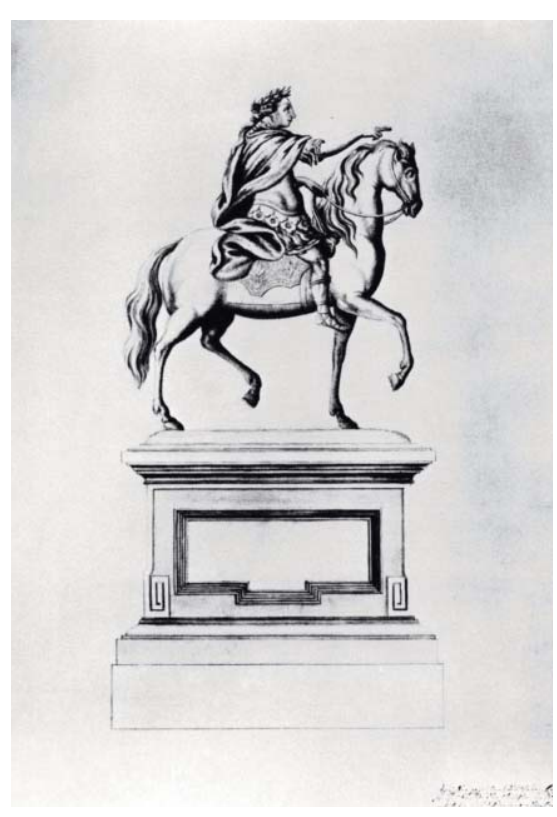

Izquierda. Figura 8: propuesta de Nüssle, 1791 (von Simson 1975: página sin especificar).

Centro. Figura 9: propuesta de Hillner, 1791 (von Simson 1975: página sin especificar).

Derecha. Figura 10: Propuesta de Pfeiffer, 1791 (von Simson 1975: página sin especificar).
Al unificar dentro de la misma obra el ámbito de lo terreno y el de lo idealizado, Schadow remite a un esquema típicamente medieval, que diferenciaba la esfera inferior o terrestre de una superior o celestial.

Entre las propuestas enviadas a concurso, la modalidad artística más habitual fue la de la escultura ecuestre; utilizando este tipo de representación se reprodujo al monarca en diferentes variantes, desde aquellas que lo retrataban de un modo humanizado y realista, presentando a un Federico avejentado, de cuerpo menudo, espalda cargada y pies pequeños (figura 8), a la encarnación de un idealizado César coronado de laurel, erguido sobre su corcel y preparado para la batalla (figura 9).

Aunque en estos conjuntos ecuestres el foco de atención recae, obviamente, en las figuras de caballo y jinete, resulta interesante analizar el papel que en ellas juegan los pedestales. En el caso de la enviada por Nüssle (figura 8), el basamento tiene prácticamente las dimensiones de un ataúd, de modo que, de un modo bastante sutil, el artista estaría superponiendo el carácter conmemorativo sobre el funerario; el pedestal es un volumen compacto, representado en perspectiva y carente de ornato. En la enviada por Hillner (figura 9), las proporciones han variado, y al aumentar la altura se pronuncia el efecto de pedestal del elemento de base.

Similar a ésta última es la propuesta de Pfeiffer (figura 10), en cuanto que representa a Federico como emperador romano, si bien en esta ocasión se ha optado por una visión más realista del monarca, al reproducir algunos de sus rasgos físicos y una presencia menos corpulenta y más relajada que en el caso anterior, así como un atuendo menos belicista.

Tassaert, sin embargo (figura 11), vuelve al modelo prusiano y retrata al monarca enfundado en uno de los uniformes de su ejército, completamente erguido sobre su caballo. La actitud hacia la vertical de Federico se corresponde con una larguísima cola en el caballo, que cae hacia el suelo sin el menor atisbo de movimiento. La altivez del jinete y la solemnidad del animal confieren un cierto estatismo al conjunto, que se alza sobre un pedestal adornado con guirnaldas, en cuya base vuelven a hacer aparición los personajes mitológicos.

Pese a las diferencias en estas esculturas ecuestres, la forma de representar la figura es prácticamente idéntica ${ }^{4}$ : sobre un pedestal de afiladas aristas, la imagen del caballo en posición de marcha y, sobre él, Federico, en actitud serena, pero realizando indicaciones con el brazo derecho levantado. La repetición de las poses de equino y jinete en todas ellas remite a una de las esculturas ecuestres más famosas de la historia, la de Marco Aurelio (figura 12). La utilización de forma recurrente de este grupo escultórico como modelo, refleja el deseo de establecer una analogía entre ambos personajes: Marco Aurelio, el emperador filósofo y Federico el Grande de Prusia, el rey filósofo.

\section{El monarca distante de Langhans}

Como recoge Alste Oncken (1981: 43), al final de abril de 1797 habian enviado sus 
Figura 11: Propuesta de Tassaert, 1797 (von Simson 1975: página sin especifi-

Figura 12: Escultura ecuestre de Marco Aurelio. Anónimo. Siglo II (autora).
Figura 13: Plano de situación de las propuestas de Carl Gotthard Langhans (1) y Heinrich Gentz (2) en la Unter den Linden. Esquema de la autora sobre extracto del plano de Berlín dibuja do en 1804 por J.C. Selter (Landesarchiv Berlin: 270, A90).

Figura 14: Derecha. Carl Gotthard Langhans, versión dórica de la propuesta presentada a concurso en 1797 (Oncken 1981: 23b).

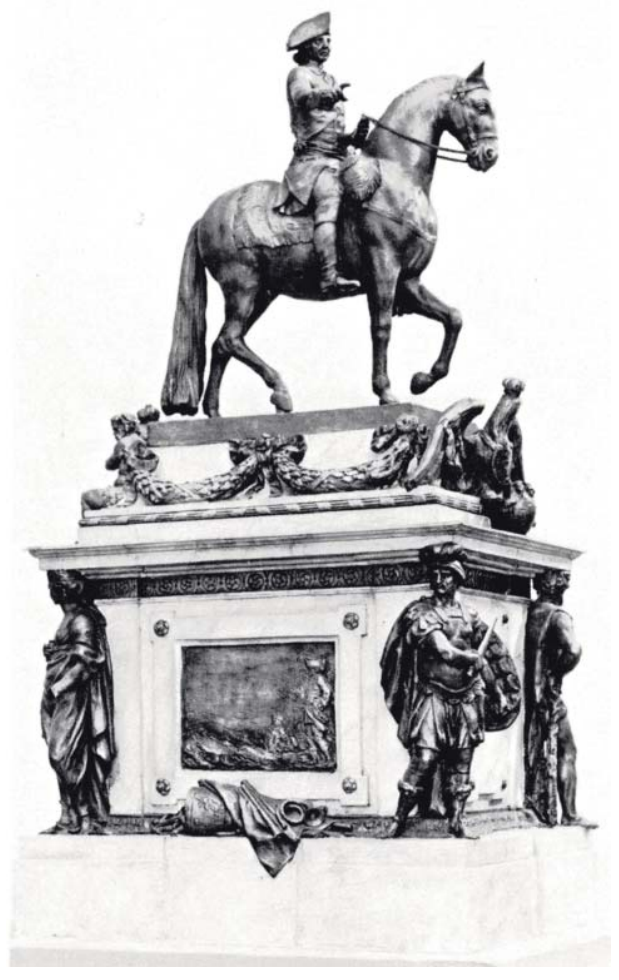

proyectos cinco miembros de la Akademie der bildenden Künste5: Langhans, Hirt, Haun, Heinrich Gentz y Friedrich Gilly.

La ubicación fijada para la instalación del monumento era un lugar en la Unter den Linden, frente al edificio que ocupaba la Academia, situada en la primera planta de las caballerizas reales.

Carl Gotthard Langhans (1732- 1808) respetó la ubicación propuesta (figura 13:1) y en ella proyectó un templo circular, rodeado por doce delgadas columnas, en cuyo interior se encontraba la estatua del rey, iluminada de forma cenital. Presentó dos versiones, una en estilo dórico (figura 14) y otra en estilo jónico.

Para la presentación de la versión jónica del templete, Langhans realizó una vista del edificio (figura 15), situándolo en el emplazamiento exacto que habría de ocupar en la Unter den Linden; un lugar relativamente cercano a la Puerta de Brandemburgo. En la imagen se puede apreciar el tratamiento que se dispensa al edificio, insertado como un objeto en la trama

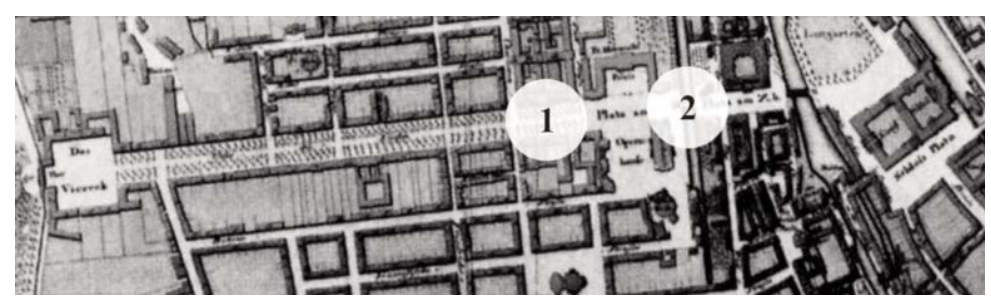

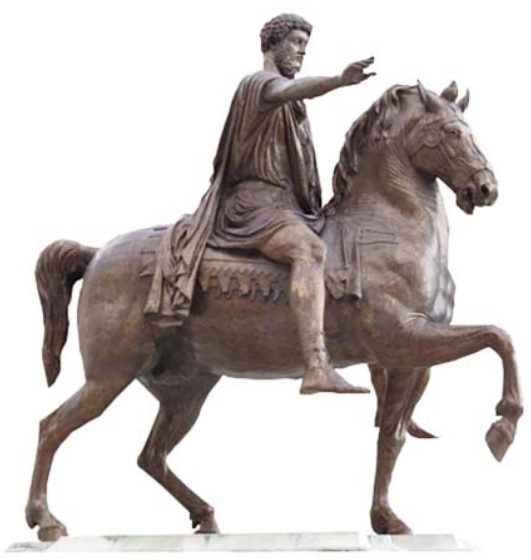

urbana, apoyado directamente sobre el terreno, sin más relación con el entorno que la que irradia su propia presencia. La escultura representativa de Federico, situada en su interior, era de tamaño algo mayor al natural, pero sin caer en la exageración. Ésta se ubicaba en el centro de la rotonda, elevada sobre un pedestal.

La elección de un punto de vista situado en el propio eje de la calle convierte las fachadas laterales de la misma en pantallas que fugan hacia un lugar ubicado detrás de la escultura del monarca; el punto de fuga en el que convergen, sin embargo, queda oculto tras las alineaciones de tilos del fondo, en las que los edificios parecen disolverse. El templete queda así dibujado sobre la arboleda de la que, a la vez, parece surgir la propia arquitectura. La estatua de Federico está elevada al mismo nivel que las copas de los árboles, mimetizándose con la naturaleza del fondo y desvinculándose al mismo tiempo del plano del suelo, en el que discurre la vida de los súbditos. Este efecto se consigue ubicando el punto de vista del observador al mismo nivel de la estatua de Federico, o si se quiere, elevando sobre otro pedestal al espectador; éste en realidad no es otro

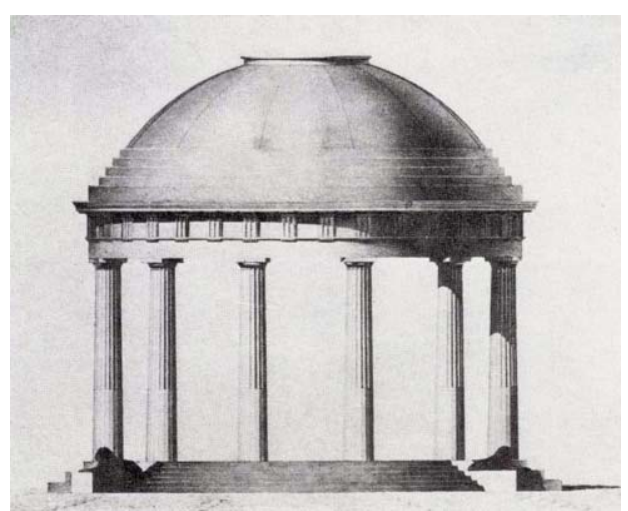




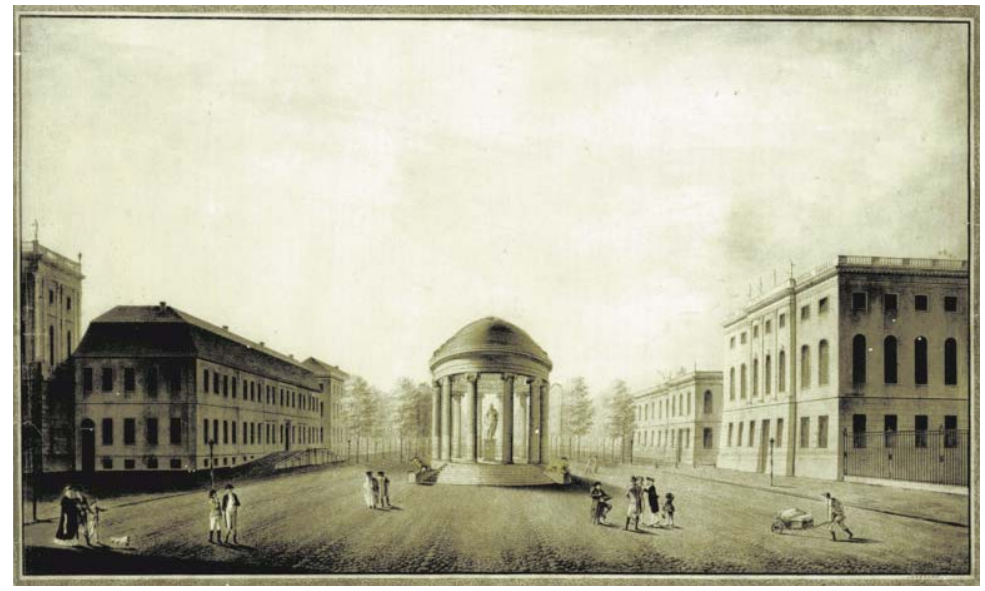

Figura 15: Carl Gotthard Langhans, versión jónica de la propuesta presentada a concurso en 1797 (Blauert y Wippermann 2007: 123).

que Federico Guillermo II, verdadero cliente del proyecto al ser el único responsable de elegir la propuesta ganadora. Langhans convierte así la vista en un duelo entre monarcas, donde el situado a este lado del cuadro domina la escena, mientras que aquél no es más que una visión idealizada y lejana.

La imagen que del monarca ilustrado proyectaba la propuesta de Langhans resultaba conveniente para Federico Guillermo II, puesto que transformaba al Gran Federico, al odioso tío que tanto lo humilló en vida, en una figura distante, incapaz ya de causar ningún daño. Esta fue, de hecho, la propuesta seleccionada por el rey para su ejecución, de todas cuantas concurrieron a concurso en la convocatoria de 1797; sin embargo, la muerte de Federico Guillermo II en noviembre de ese mismo año, dejó las obras en suspenso.

La implicación urbana del templete proyectado por Langhans es muy pequeña, pese a ubicarse en el centro de la principal arteria de la ciudad; ésta se reduce, de hecho, al impacto que el objeto produce en el entorno inmediato. La vista ha sido tomada en dirección oeste- este, es decir, hacia la Puerta de Brandemburgo (figura 16), proyectada y construida por el propio Langhans unos años antes (1788- 1791); sin embargo, el autor elude cualquier referencia a este otro monumento, sin lugar a dudas el mayor emblema urbano de la ciudad en aquel momento. La inclusión de la portada clasicista en la representación hubiese establecido una comparativa entre ambos monumentos, en la que el templete levantado en honor a Federico II hubiese resultado desfavorecido.

\section{El remanso estético de Heinrich Gentz}

Según Alste Oncken (1981: 43), la propuesta de Heinrich Gentz (1766- 1811) está basada en el proyecto de Langhans, puesto que opta, al igual que éste, por un templete circular para albergar el monumento. Sin embargo, las diferencias entre ambos proyectos son notables. En primer lugar, Langhans se inspira en "el Erecteion, el pórtico de Filipo de Macedonia en Delos y el Partenón", según recoge el propio Oncken, mientras que Gentz reproduce una variante del templo de Vesta en Roma, sustituyendo el muro de la cella por una fila adicional de columnas, que se suma a la existente en el templo original, a la vez que reduce el número de soportes perimetrales de dieciocho a doce. El orden utilizado es el correspondiente al modelo, es decir, el corintio.

No obstante, la diferencia fundamental entre las dos propuestas no procede de la mera representación formal del objeto arquitectónico, sino que deriva de una concepción distinta sobre la forma de observarlo; mientras que Langhans introduce el templete en la escena urbana con objeto de embellecerla, Gentz utiliza la capacidad del edificio para producir placer estético como instrumento de formación.

La teoría estética desarrollada por Heinrich Gentz es producto de las diversas corrientes que participaron en su formación como arquitecto. Gentz se introdujo en la profesión de la mano de Carl von Gontard (1731- 1791), de quien recibió sólidos conocimientos en los principios del tardobarroco fridericiano. A la educación oficial recibida de Gontard, sumaría la influencia de los numerosos círculos de discusión que proliferaron en Berlín durante el último tercio del siglo XVIII.

De especial relevancia para la creación de su personalidad artística resultaría el vínculo que unió a su hermano Friedrich con Mosses Mendelssohn, buque insignia del pensamiento ilustrado en la capital prusiana hasta su muerte en 1786 . Mendelssohn, como indica Rüehle (1997: 22), pese a encontrarse intelectualmente vinculado a la Ilustración, contribuiría a sustraer a la belleza de las pretensiones de la razón, ensanchando el camino que conduciría a la estética kantiana del gusto. El papel formativo que Mendelssohn asignaba a la estética puede resumirse en la frase: "no solo estamos destinados a mejorar las fuerzas del entendimiento y de la voluntad, sino también a acostumbrar al sentimiento, a través del placer sensible, a una perfección más alta" Rüehle (1997: 23).

A través de Mendelssohn entraría Heinrich Gentz en contacto con la filosofia de Immanuel Kant 6 . Como indica Berghahn (2012: 377), Gentz habría sido el primer arquitecto europeo en trasladar las productivas discusiones sobre el pensamiento kantia- 
Figura 16: Vista de la Puerta de Brandemburgo. Acuarela de Daniel Berger sobre original de Peter LudStadtmuseum Berlin: GRD 64/104) wig Lütke (Stiftung

no al ámbito de la arquitectura, al aplicar a la construcción el principio de autonomía de la obra de arte, que Kant había establecido en la Kritik der Urteilskraft ${ }^{7}$ bajo la idea de una finalidad sin fin (Zweckmässigkeit ohne Zweck). Sin embargo, para unir los aspectos de intemporalidad (Entzeitlichung), falta de contenido (Inhaltslosigkeit) y abstracción (Abstraktion) que caracterizaban a este principio en una estética de la arquitectura, era necesaria una mediación. En este sentido, Heinrich Gentz habria encontrado apoyo en otros teóricos, que contribuirian a la materialización de su pensamiento en una teoría concreta; entre ellos destacan las figuras de Francesco Milizia (1725- 1798) y Karl Philipp Moritz (1756- 1793).

El primero, en tanto que representante de la teoria de la arquitectura ilustrada, buscaba la formulación de una filosofia de la arquitectura, un ennoblecimiento teórico en cuyo centro se encontraba el arquitecto como formador de la sociedad burguesa. Según Berghahn (2012: 378), mediante la publicación de sus Principi di architettura civile (1781), Milizia emancipaba a la arquitectura del paradigma de la cabaña primitiva y de la especulación antropológica en torno a la esencia de los órdenes de columnas, para elevarla a las más altas instancias de la vida pública, a la vez que le asignaba un papel distinto al que habia ocupado en el régimen absolutista, al someterla a debate público entre todos los ciudadanos.

Karl Philipp Moritz ejercería una influencia notable no solo sobre Heinrich Gentz, sino sobre el grueso de los arquitectos alemanes nacidos en torno a 1770. El canal de difusión utilizado por Moritz para formar a la nueva generación de arquitectos sería la serie de conferencias que pronunció en la Akademie der Künste desde su nombramiento como catedrático de la recién crea-

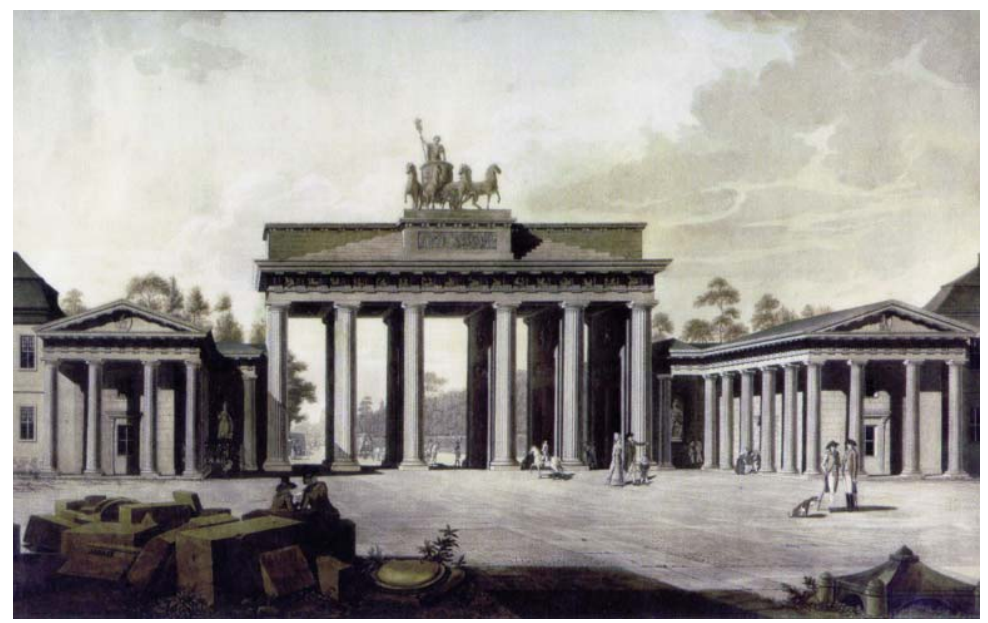

da disciplina Teoría de las bellas artes y ciencias de la antigüedad $^{8}$ en 1789 (Fendt, Sedlarz, y Zimmer 2014: 141).

En el año 1788 el ensayista y poeta regresa a Berlín tras una estancia de dos años en Italia, y comienza a transmitir una particular teoría estética obtenida a partir de la observación de la ciudad de Roma; mediante su descripción de la metrópoli italiana, Moritz forma, como indica Berghahn (2012: 357), la imagen del espacio en movimiento, al tratar la ciudad como un paisaje simbólico. Para Moritz, Roma es especial debido a sus signos específicos y su estructura espacial, que se construye a través de una superposición palimpséstica de signos antiguos y modernos. En esta superposición, los objetos han perdido su significado original, adquiriendo nuevas connotaciones que son el resultado de la distinta percepción que de ellos, en las diferentes épocas, tiene el hombre.

El análisis que de la ciudad realiza implica una redefinición del concepto de simbolo; interpretar el simbolo supone traducirlo al presente, darle un significado actual, no en función de un lenguaje surgido de los tratados de arquitectura, sino de la propia capacidad expresiva del objeto. Con ello, Moritz reivindica la autonomía de la forma frente a la heteronomía de la función; lo importante no es el uso que un determinado edificio tuviera en el pasado, sino lo que ahora representa para nosotros. Esto implica, a su vez, la definición de un nuevo sistema de relaciones, en el que el sujeto no es más un observador pasivo que absorbe la belleza, sino un ser autónomo que contribuye a crearla, al hacerla subsidiaria de su propia percepción.

Por otra parte, como recoge Jordi Claramonte (2006), la observación de la belleza tiene para Moritz la capacidad de trasladar al individuo a una existencia superior, liberándolo de las limitaciones de su cotidianeidad:

"Cuando lo bello atrae hacia sí nuestra contemplación, la sustrae un tiempo de nosotros mismos y hace que nos parezca que nos perdemos en el objeto bello; y precisamente esta pérdida, este olvido de nosotros, es el más alto grado de goce puro y desinteresado que proporciona lo bello." (Moritz en Claramonte 2006: 40)

Moritz reconoce lo bello como algo externo al hombre, sin embargo, le atribuye la capacidad de hacer aflorar lo noble y lo bueno, que están dentro de él, así como de ayudarle a ejercitar su capacidad de crítica. La observación de lo bello adquiere, por lo tanto, un valor formativo: 


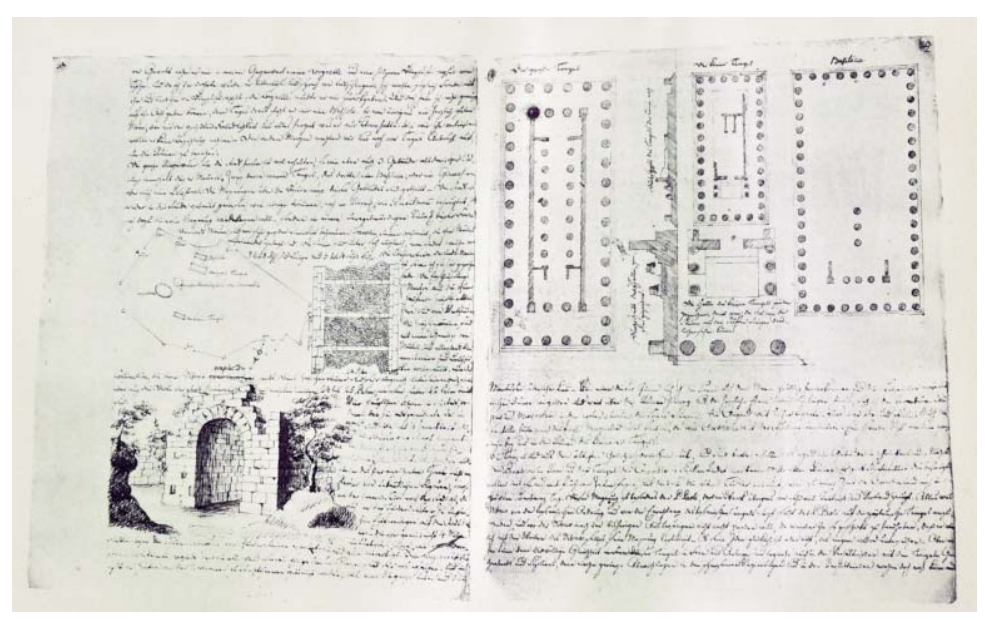

Figura 17: Cuaderno de apuntes de Heinrich Gentz, extraido del libro "sobre Sicilia" (Doebber 1916: Il. 7).

Figura 18: Esquema realizado sobre la planta de la propuesta presentada a concurso en 1797 por Heinrich Gentz (Doebber 1916: Il. 13 y autora).
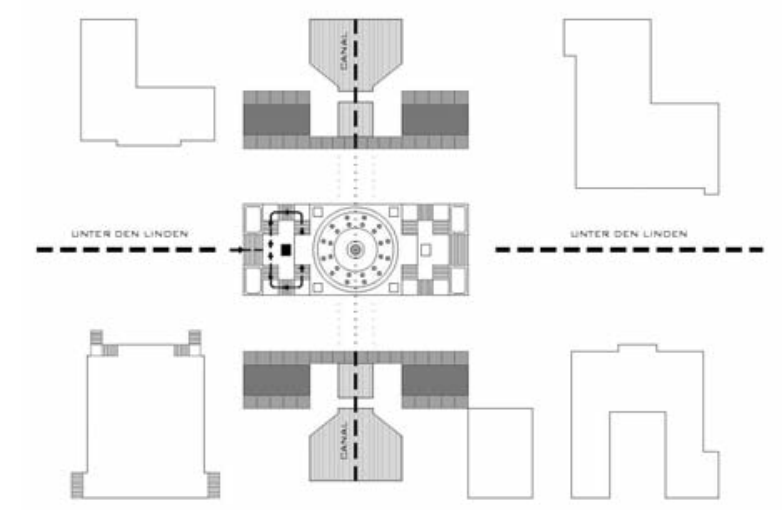

por la visión que de Roma transmitía Moritz en sus conferencias, y que se prolongó durante cinco años, llevándolo, además de a Italia, a Sicilia, Holanda, Francia e Inglaterra, y en el que tuvo ocasión de visitar, no sólo los monumentos antiguos, sino las construcciones más recientes del neoclasicismo europeo.

Su propuesta para el monumento a Federico II de 1797 puede entenderse como una compilación de todas estas influencias.

En primer lugar, Gentz trata de incluir el edificio dentro del sistema de fuerzas que definen el carácter de la ciudad, por lo que busca un emplazamiento que dinamice las relaciones entre la construcción y el entorno; para ello, desplaza su proyecto sobre el eje de la calle hacia el este, en relación a la ubicación de la propuesta de Langhans, hasta situarlo un poco más allá de la Casa de la Ópera (figura 13:2), coincidiendo con el canal que, por aquel entonces, discurría de forma perpendicular a la Unter den Linden.

Con la ubicación en este emplazamiento, Heinrich Gentz define el monumento en base a dos ejes perpendiculares, determinados por la Unter den Linden y el canal que discurría de forma soterrada bajo ella (figura 18). Sobre el primero ubica el programa del monumento; sobre el segundo, el del enterramiento. Ambos se articulan mediante la acción del templete circular que, a modo de rótula, estructura el movimiento en torno a los dos ejes.

La propuesta de Gentz (figura 19) está formada por tres grandes piezas: un paralelepípedo de base rectangular, concebido como un basamento pétreo, en el que se ha excavado el monumento funerario, a la vez que sirve de apoyo al templo, y dos piezas laterales que forman las fachadas del complejo a la Unter den Linden.

El objeto fundamental del conjunto continúa siendo el templo; el resto de elementos- los leones enfrentados en la base, los
Figura 19: Derecha, propuesta presentada a concurso por Heinrich Gentz en 1797 (Doebber 1916: Il. 13).

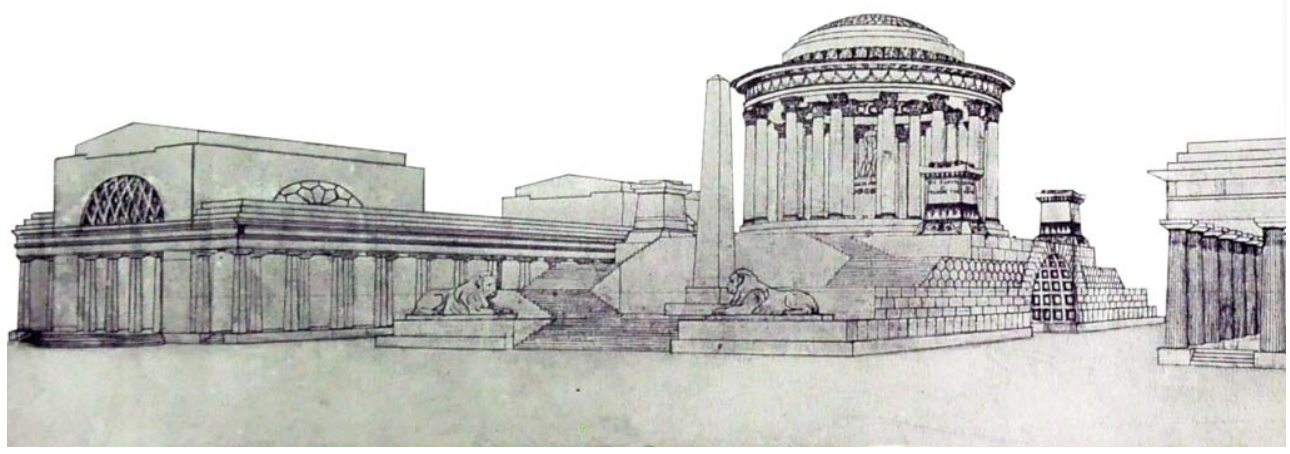




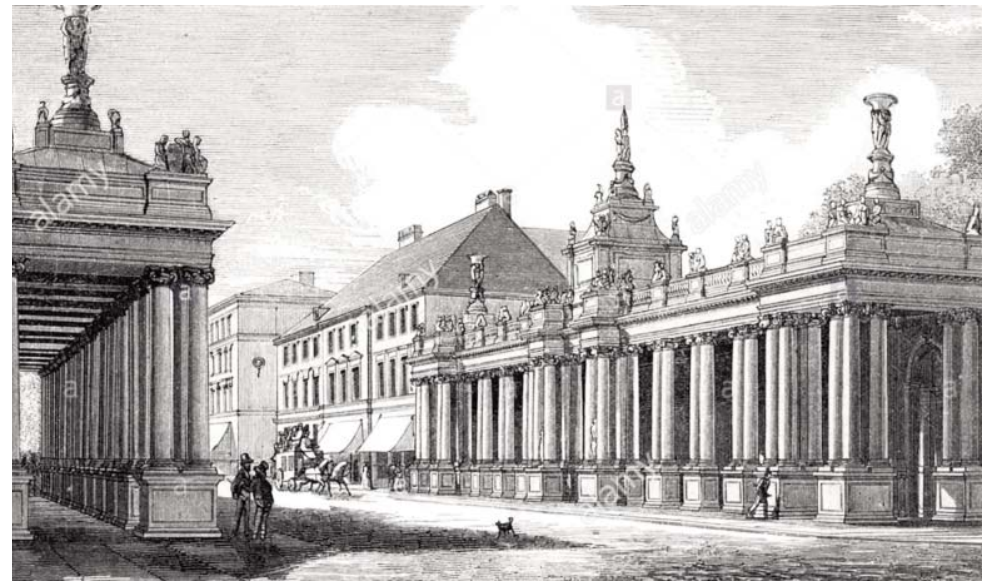

Figura 20: Königskolonaden. Carl von Gontard (1777-1780). www.alamy.com/stoc $k$-photo-geography-travel-germany-berlinkoenigskolonnaden (visitado $31 \mathrm{abr}$. 2017). obeliscos, los escalones tallados en el basamento, los altares para sacrificios- no son más que instrumentos de los que Gentz se sirve para guiar al observador en su acercamiento a la rotonda, en cuyo centro, elevada sobre un basamento circular, se encuentra la escultura conmemorativa de Federico, en forma de dios desnudo.

Pese a que la estatua se encuentra alineada con el eje de la Unter den Linden, la interposición de sendos obeliscos en los extremos de la base obstaculiza la visión de la misma desde el centro de la calle. Con este gesto, Gentz sustrae la escultura del ajetreo de la vida diaria, aislando su belleza del mundanal ruido, a la vez que invita al potencial observador a emprender un camino que comienza en la base, en la línea definida por los dos leones enfrentados, y asciende a través de los distintos tramos de escaleras hasta la base del templo. Con ello, define diferentes niveles de aproximación e intimidad, que funcionan como velos que es necesario apartar para acceder a situaciones espaciales distintas.

Frente al remanso creado en el centro de la calle para observar el monumento, Gentz canaliza el movimiento en los laterales de un modo fluido, mediante un sistema de logias que envuelven los volúmenes creados por él para conformar las fachadas a la Unter den Linden. Las hileras de columnas de Gentz en esta propuesta son herederas de las columnatas de Gontard (figura 20), quien las usaba de forma recurrente desde la década de los años cincuenta. Éste las habría tomado a su vez, como indica Schmitz (1914: 24), de la escuela francesa en Italia. Sin embargo, pese a las similitudes entre ambos, puede apreciarse la evolución que Heinrich Gentz supone respecto a su maestro, no solo en lo que a la depuración de los elementos constructivos se refiere, sino a la propia disposición de los mismos, al renunciar al orden doble, típicamente barroco, usado por Gontard.

La vista que Gentz envió a concurso elude la representación de cualquier elemento preexistente en la ciudad, lo que confiere a la imagen un halo de irrealidad que contribuye a reforzar el concepto de autonomía. Sin embargo, la falta de referencias espaciales llevó a Adolph Doebber (1916: Il. 13), autor del único monográfico que sobre Heinrich Gentz se ha publicado, a calificar el proyecto de "inacabado", y a tratar de corregir la desubicación del mismo con la inclusión en la escena (figura 21), no solo del palacio del principe Heinrich y la Zeughaus, edificios que flanqueaban las fachadas del monumento en su lado norte a izquierda y derecha respectivamente, sino a completar el propio monumento con elementos decorativos, e incluso a ataviar la figura del dios desnudo situado en el centro de la rotonda con un uniforme prusiano. Doebber remata la escena con ambientación de paseantes, que caminan despreocupadamente por la calle y elementos vegetales, que suavizan las duras aristas de las logias laterales. Se podría decir que, al "acabar" el dibujo de Heinrich Gentz, Adolph Doebber termina definitivamente con la atmósfera de intelectualidad que sobre él planea, a la vez que restituye el

Figura 21: Reconstrucción de Adolph Doebber de la propuesta de Heinrich Gentz de 1797 (Doebber 1916: Il. 13).

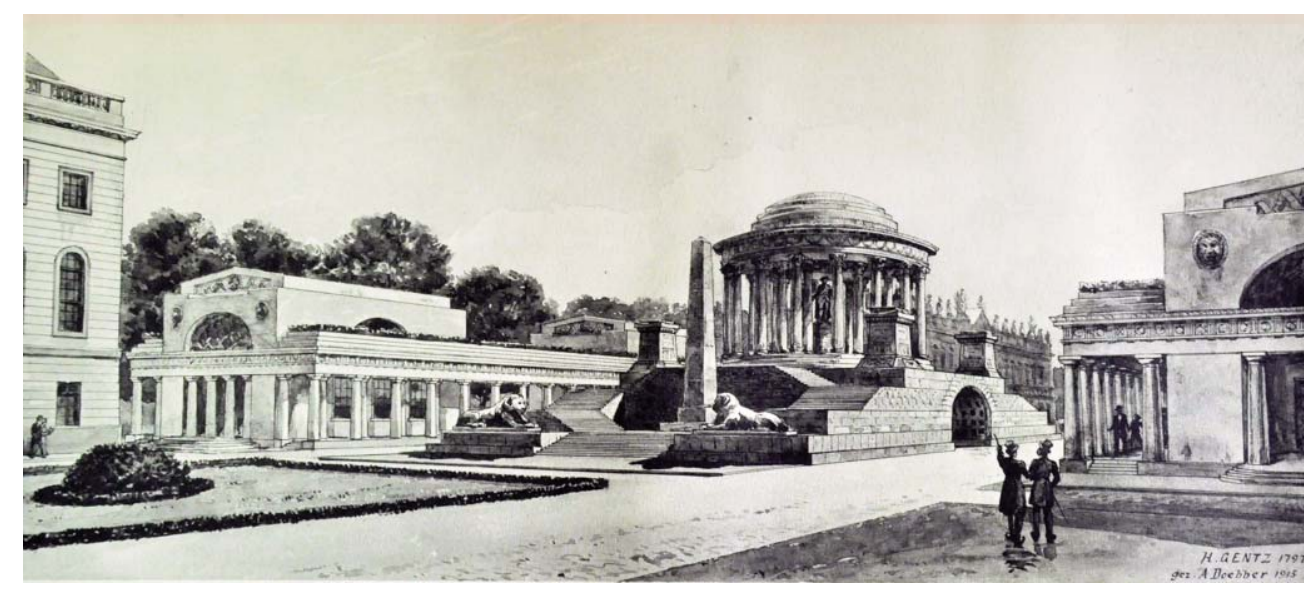




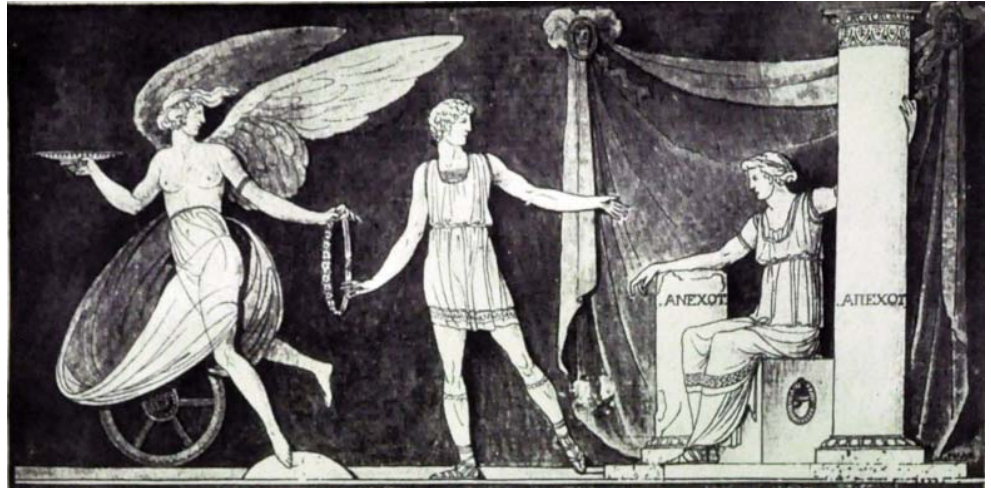

Figura 21: Friedrich Gilly. Dibujo dedicado a Heinrich Gentz, 1790 (Doebber 1916: Il. 5).

Figura 23: Esquema de localización de la Leipziger Platz sobre plano de Berlín dibujado en 1804 por J.C. Selter. Grabado coloreado (Landesarchiv Berlin: 270, A90). remanso estético creado por el arquitecto, a la vida real.

\section{E1 templo a la ley moral de Friedrich Gilly}

El nombre de Friedrich Gilly (1772- 1800) se encuentra indisolublemente unido al de Heinrich Gentz; ambos fundaron en 1799 la Privatgesellschaft junger Architekten ${ }^{9}$ y colaboraron profesionalmente en la realización del edificio para la nueva sede de la Moneda $^{10}$. A la relación profesional habria que sumar la familiar, derivada del matrimonio que unió a los hermanos de ambos, Friedrich Gentz y Mina Gilly. Según Alste Oncken (1935: 29), fue Heinrich Gentz quien introdujo a Friedrich Gilly en el circulo de artistas de Berlin. Oncken refiere a un dibujo que Heinrich Gentz envió a Gilly desde Sicilia, donde se encontraba en 1790 , dedicado con la frase "a mi querido amigo", para acreditar una relación perso- nal entre ellos, que iría más allá de los vínculos profesional y familiar (figura 22).

Friedrich Gentz, por su parte, habria funcionado en la vida de Friedrich Gilly como correa de transmisión del pensamiento kantiano, al trasladar las discusiones de los círculos filosóficos berlineses a conversaciones con su joven cuñado. A partir de aquí, la relación de la producción arquitectónica de Friedrich Gilly con la filosofia, y fundamentalmente con la obra filosófica de Immanuel Kant, ha sido apuntada desde Wilhelm Niemeyer (1912) hasta Cord- Friedrich Berghahn (2012), aunque ninguno de ellos indica de qué forma se materializa esta influencia.

La cercanía entre Heinrich Gentz y Friedrich Gilly puede rastrearse además a través de las similitudes que las propuestas de ambos para el monumento a Federico II de 1797 presentan en su origen, aunque el resultado final sería muy diferente en los dos casos.

El proyecto de Friedrich Gilly busca una implicación urbana aún mayor que el de Heinrich Gentz; para conseguirla, renuncia al emplazamiento propuesto en las bases del concurso y se traslada a la Leipziger Platz, el espacio que definía el límite de Berlin en el camino hacia Potsdam, lugar en el que Federico II había instalado su segunda residencia (figura 23).

El octógono de la Leipziger Platz cumplía mejor que ningún otro espacio de la ciudad

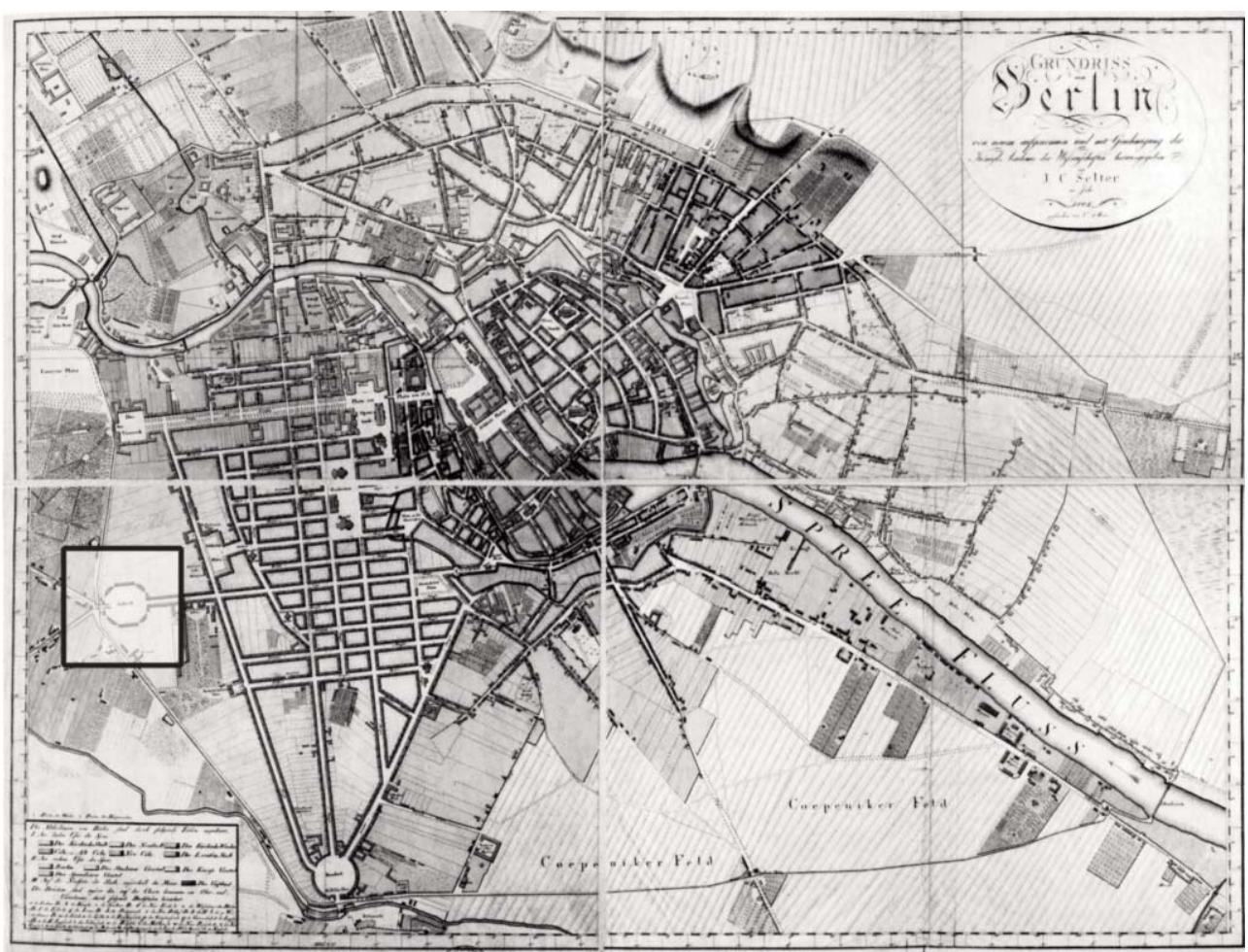




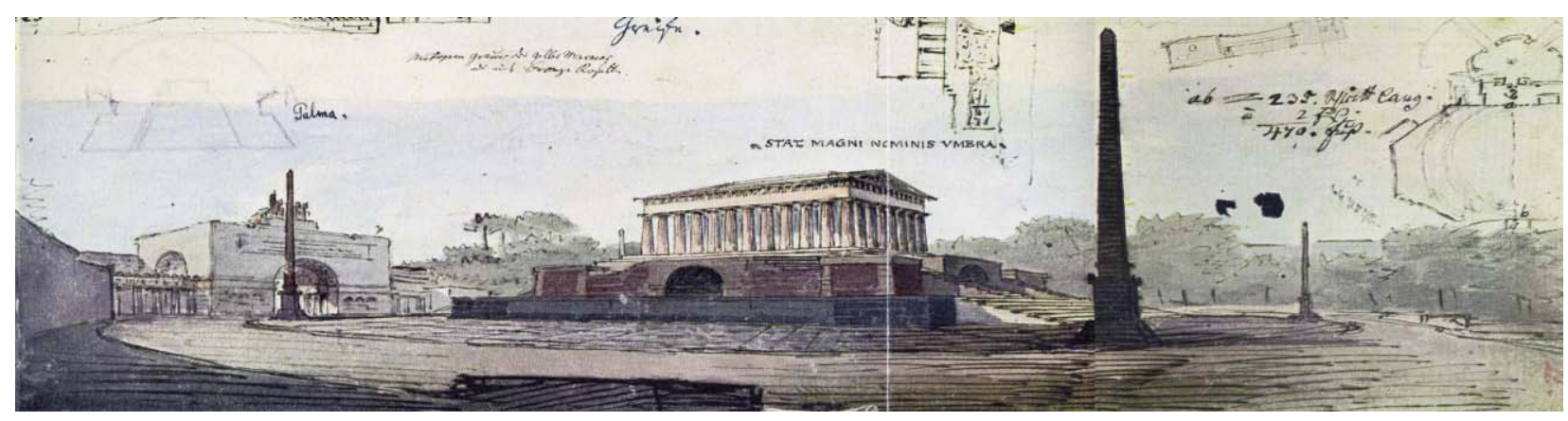

Figura 24: Friedrich Gilly, propuesta previa para el proyecto presentado a concurso en 1797 (Rietdorf 1940: 56b).
Figura 25: Transformación de las fachadas laterales en frontales. Esquema realizado por la autora. las exigencias de "tamaño, representatividad y decoro", que para la instalación del monumento estableció Friedrich Gilly (1994: 131- 132).

En primer lugar, el objeto debía ser "muy grande en escala. Probablemente el mayor de la ciudad" (Gilly 1994: 135); el edificio podía estar, por lo tanto, en el límite de la ciudad, pero no fuera de ella, puesto que las exigencias de Gilly requerian de un entorno cosmopolita en el que desarrollar su concepto de monumentalidad. Observando el plano de Berlín de la época se puede constatar que, efectivamente, existían pocos lugares públicos que pudieran ofrecer semejante cantidad de espacio libre.

La localización en esta plaza garantiza igualmente la representatividad, puesto que el octógono de la Leipziger Platz "marca el final de una de las calles más largas y bellas de la ciudad, y al forastero que entre desde una de las carreteras más usadas y de una conveniencia militar mayor entre las dos residencias, le producirá una impresión favorable de la capital." (Gilly 1994: 131)

Finalmente, la escasa densidad constructiva de la zona impedía que el monumento entrase en competencia, en cuanto a tamaño o representatividad, con cualquier otro edificio aledaño; no obstante, de forma complementaria a la construcción del monumento en sí, Gilly propone un adecentamiento de las zonas limítrofes, mediante el derribo de algunos edificios residenciales "sin pretensiones", la mejora del pavimentado y el plantado de árboles (Gilly 1994: 133).

Sobre el octógono de la Leipziger Platz, Friedrich Gilly crea un entorno propio para el monumento; en primer lugar, proyecta una portada de acceso coincidiendo con el limite de la ciudad, a la que llama "Puerta de Potsdam".

La propuesta inicial de Friedrich Gilly en este emplazamiento (figura 24) es muy similar al proyecto presentado por Heinrich Gentz puesto que, al igual que aquel, está formada por un sólido rectangular, en cuyo interior se ha excavado la gruta que acoge el monumento funerario, a la vez que sirve de basamento al templo, concebido como monumento representativo. Estos dos sistemas se organizan también en base a dos ejes perpendiculares asociados a ellos: uno longitudinal, que conecta con una calle transitada, sobre el que se encuentran las escaleras de acceso al templo, y uno transversal, que conduce al enterramiento.

La diferencia fundamental entre ambas propuestas radica en la forma del monumento, para el que Gilly recurre a un templo de planta rectangular, frente al tholos utilizado por Heinrich Gentz. A ello hay que sumar un elemento de diferenciación más, que deriva del propio emplazamiento. Como Gilly no cuenta en esta ubicación con ningún elemento que determine de forma natural la perpendicular a la callecomo ocurría con el canal en la propuesta de Heinrich Gentz-, se sirve de los frentes del monumento para definirla; para ello, 
Figura 26 Leo von Klenze. Dibujo del alzado de la propuesta de Friedrich Gilly para el monumento a Federico II (Arenhövel 1979: 302).

Figura 27: Planta de la propuesta inicial de Friedrich Gilly para el proyecto presentado en 1797 (Rietdorf 1940: 56b).

Figura 28: Sección longitudinal del templo en la propuesta inicial de Friedrich Gilly para el proyecto presentado en 1797 (Rietdorf 1940: 56b).

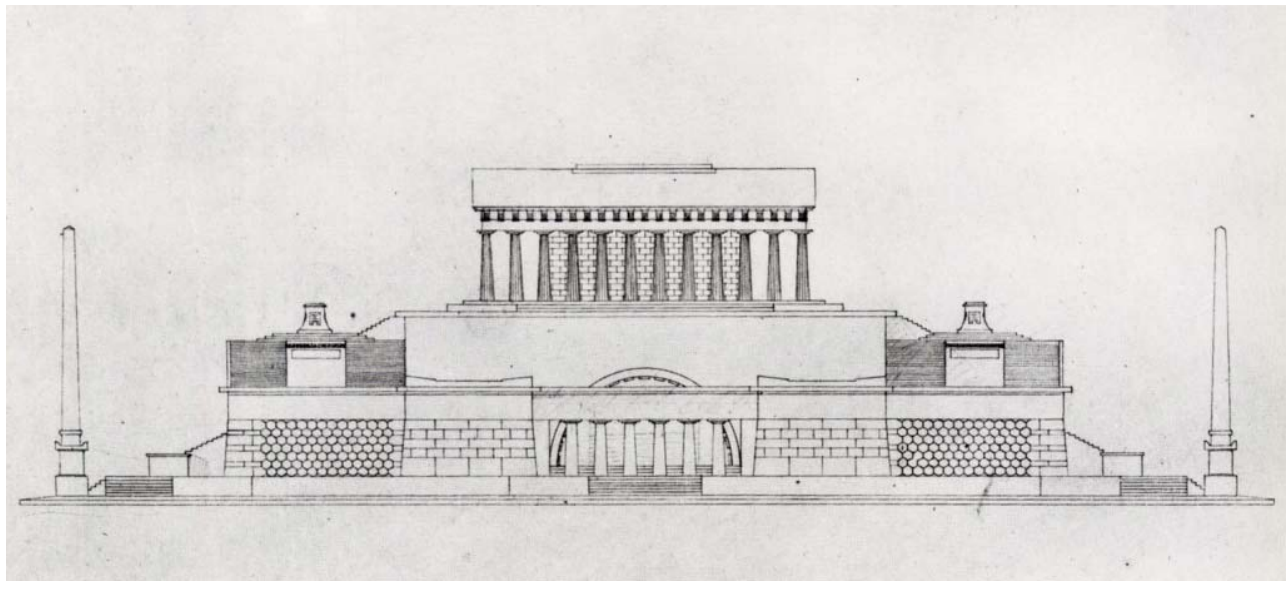

descompone el volumen del templo en planos verticales independientes, convirtiendo de este modo todas las fachadas del edificio en frontales. Esto se consigue, por una parte, utilizando un número par de columnas en el lateral- doce en concreto-, de modo que el eje de simetría coincida con un intercolumnio y pueda penetrar en el interior del edificio (figura 25).

Por otra parte, el uso de un número reducido de soportes acaba con la visión del paño longitudinal como continuidad de elementos seriados, casi ilimitados, según la concepción griega, para dar paso a una fachada que, ahora si, puede ser abarcada en su totalidad de forma frontal. La condición de frontalidad es reforzada en cada uno de los laterales mediante la utilización de obeliscos que, al ubicarse en parejas flanqueando el edificio, contribuyen a enmarcar cada uno de los frentes (figura 26).

Sin embargo, pese a la imagen que al exterior proyecta el edificio, el paralelepípedo de base rectangular del templo es una carcasa que guarda en su interior un núcleo centralizado, similar al utilizado por Gentz, según recogen los bocetos realizados por Gilly para esta propuesta (figuras 27 y 28).
No obstante, en algún momento del proceso, Friedrich Gilly introdujo cambios sustanciales que modificaron el proyecto de forma radical y conducirian a la definición de la propuesta definitiva.

En la perspectiva presentada a concurso (figura 29) se observa, respecto a la propuesta anterior, la aparición de un zócalo ciclópeo, que rodea el conjunto y permite ser atravesado, al haber sido sustituida la masa mural del centro por dos filas de columnas. El paralelepípedo que contiene en su interior el monumento funerario ha ganado en altura, convirtiéndose en un volumen de afiladas aristas, acabado en un color más claro que el muro perimetral, a cuyos laterales se han adosado las escaleras de ascenso al templo. Éste, por su parte, mantiene al exterior la apariencia formal de la propuesta previa, aunque ahora se percibe como un elemento mucho más liviano, al encontrarse en una posición más elevada y haber sido realizado en una blanquísima piedra que lo hace fundirse con las nubes del fondo, hasta el punto de parecer levitar sobre la escena.

Pese a que el templo mantiene al exterior básicamente la misma apariencia que en los dibujos previos, el interior del mismo
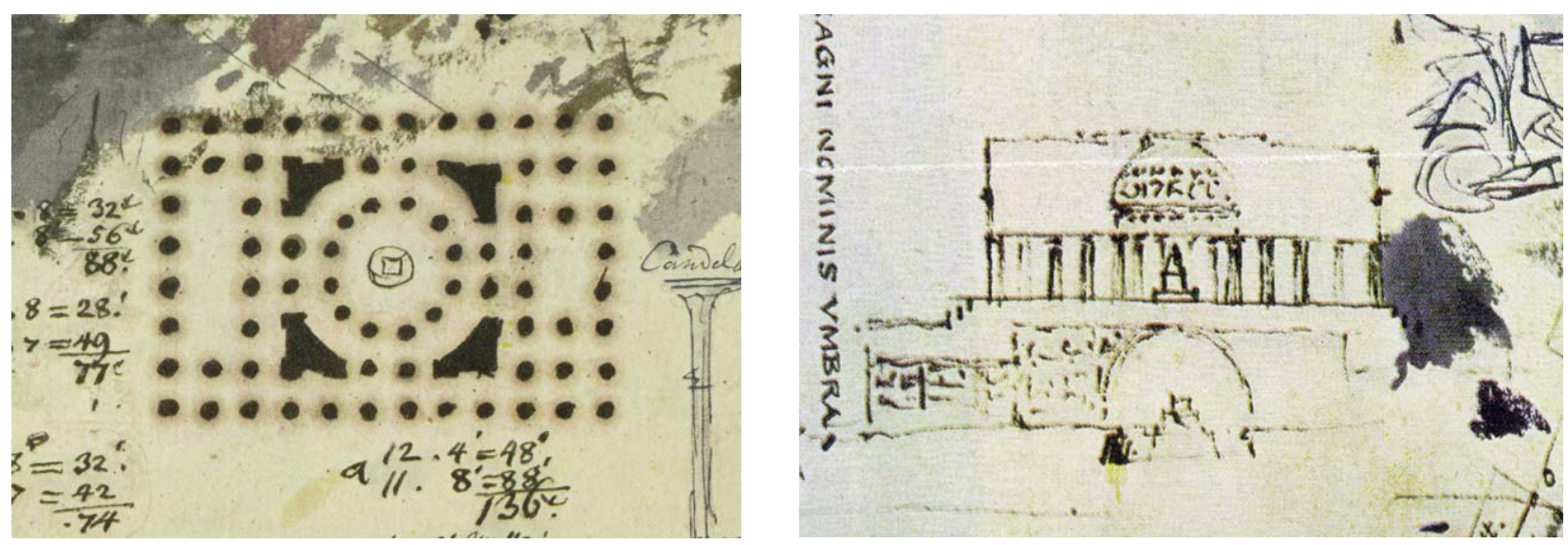
Figura 29: Friedrich Gilly. Propuesta para el monumento a Federico II. Perspectiva (Staatlichen Museum zur Berlin, Kupferstichkabinett: SZ Gilly 5).

Figura 30: Planta de la propuesta presenta da a concurso por Friedrich Gilly, 1797 (Rietdorf 1940: 58).

Figura 31: Derecha, Friedrich Gilly. Propuesta para el monumento a Federico II. Vista interior de la cella (Rietdorf 1940: Il. 48).

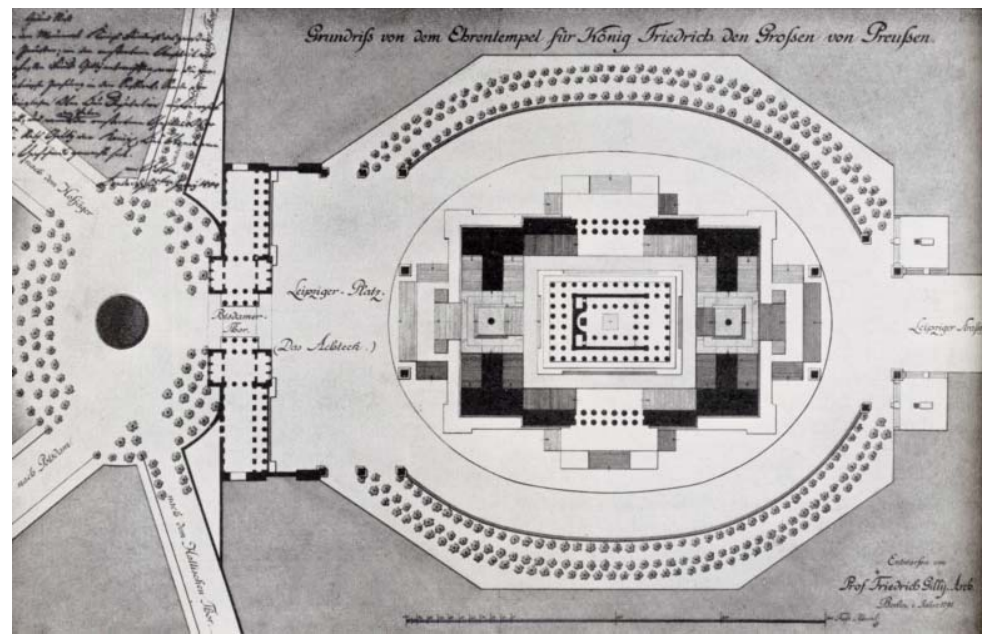

ha sido transformado; en la propuesta definitiva, Friedrich Gilly abandona la organización centralizada en favor de una planta longitudinal (figura 30).

La explicación a este cambio podemos encontrarla en uno de los bocetos del autor, en el que éste escribió a modo de apunte: "hípetro de Júpiter, legislador del cielo" (Gilly 1994: 135). El templo de la propuesta presentada a concurso es, en efecto, un templo hípetro, es decir, está dividido al interior en tres naves, mediante la interposición de dos filas de columnas en sentido longitudinal, y abierto al exterior a través de un lucernario practicado en la cubierta, ubicado sobre la nave central (figura 31).

Friedrich Gilly recoge en el templo dedicado a Federico II la descripción de Vitruvio del Olimpeion, el templo ateniense dedicado a Júpiter Olímpico:

"El hypetros tiene diez colunas en el pronao y pórtico; todo lo demás como el dipteros; pero dentro tiene dos órdenes de colunas, uno sobre otro, apartadas de la pared en rededor como pórticos de peristilos: el medio descubierto y sin techo algu-

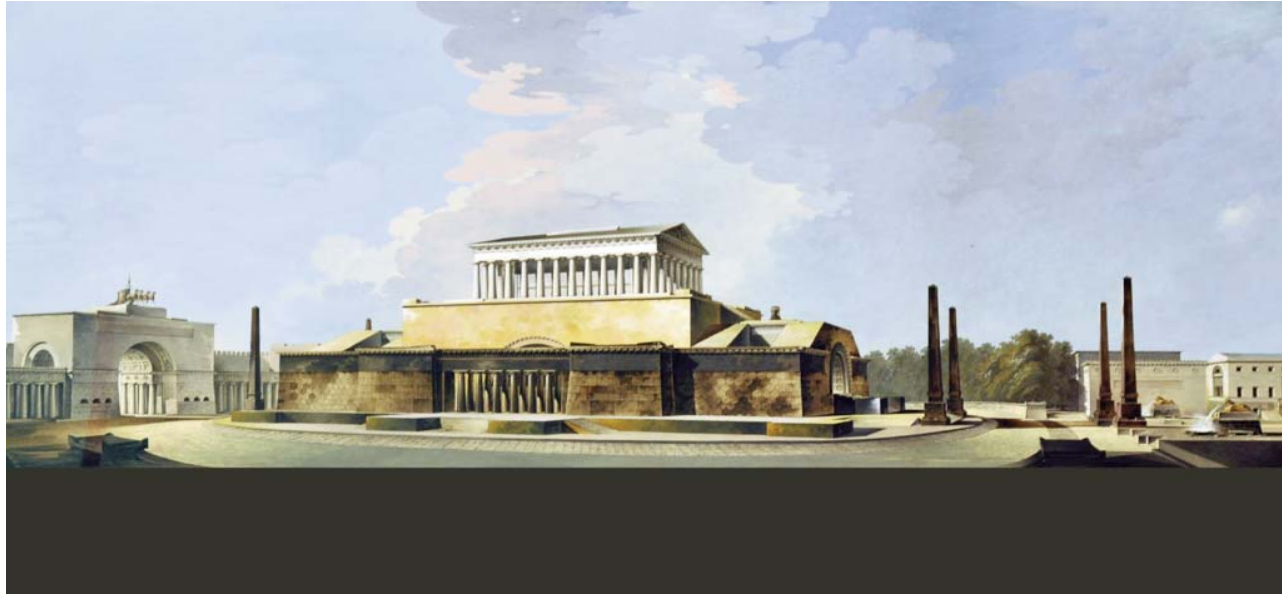

no; y puerta a los dos cabos en pronao y póstico. En Roma no hay ejemplar de este Templo, pero le hay en Aténas de ocho colunas en la frente, y es el de Júpiter Olimpico." (Vitruvio 1787: 63)

Las columnas del Olimpeion pertenecian al orden corintio, sin embargo, Friedrich Gilly renuncia a este estilo, así como a la superposición de órdenes al interior, y justifica esta decisión de la siguiente manera:

"Nada de corintio ni rico esplendor. La dignidad del sujeto en sí misma precede a todas las demás consideraciones. El verdadero esplendor debe ser la simple belleza; lo más simple posible; una grandeza reverencial, lejana a cualquier atractivo sensual, que conduzca al aspecto del objeto en sí mismo y permanezca como algo no más allá de un marco apropiado para el cuadro. En toda su sencillez, el aspecto externo debe mostrar que ha sido construido para preservar una forma simple, un inolvidable objeto para la posteridad, percibido por la fuerza de sus inquebrantables proporciones; y así aparecerá como un único monumento, uno que merece interesar a toda la humanidad." (Gilly 1994: 135)

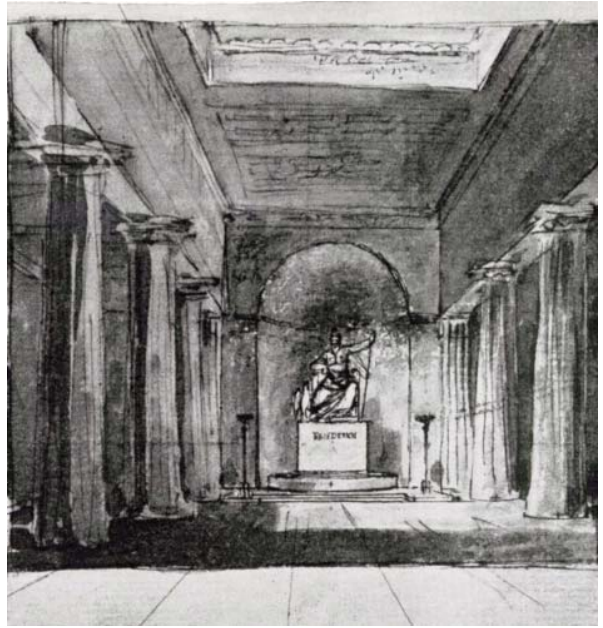




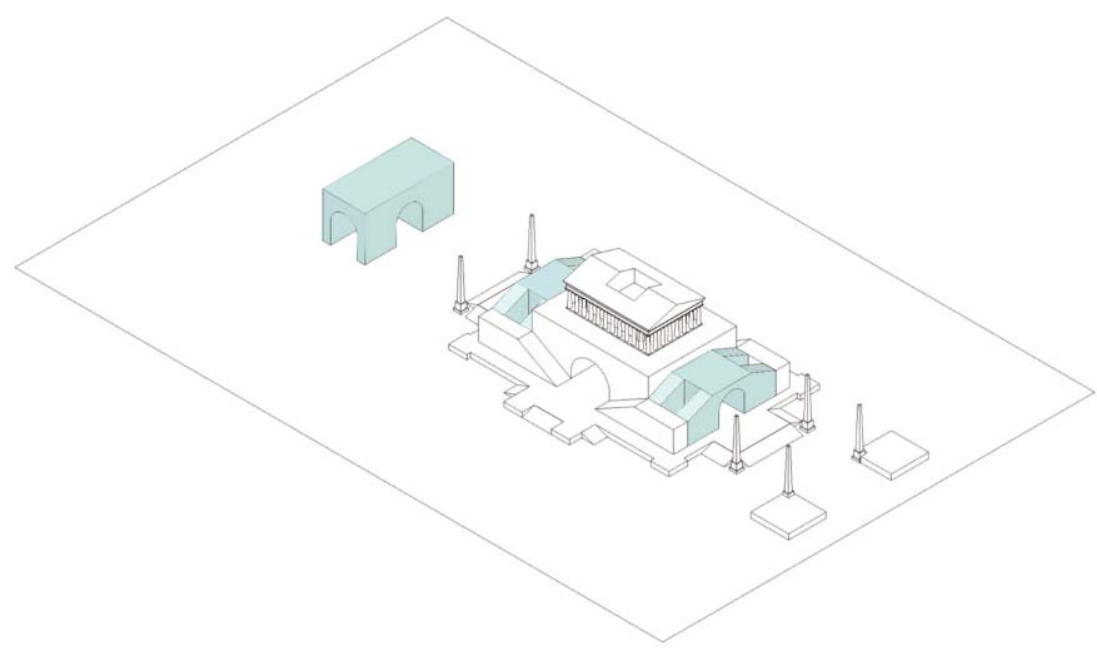

Figura 32: Analogía que determina el eje longitudinal. Esquema de la autora.

Figura 33: Movimiento en torno al eje longitudinal. Esquema de la autora.
Con la recreación de este templo en honor a Federico II, Gilly identifica al monarca prusiano con Júpiter, "el legislador del cielo", asignando con ello a aquel las atribuciones de éste: Júpiter es el legislador del cielo, al igual que Federico es el legislador- en grado sumo- de la tierra. Con este gesto, Gilly convierte al rey ilustrado en filósofo en el sentido kantiano del término, puesto que para el pensador de Königsberg, el filósofo "no es un teórico ensimismado en sus razonamientos, sino un legislador que legisla sobre la razón humana" (Paulsen 1902: 112). Federico II es, por lo tanto, reconocido de nuevo como gobernante filósofo, algo que, como se ha visto, no suponía una novedad. Sin embargo, el proyecto de Gilly, a diferencia de las propuestas anteriores, que atribuian al monarca facultades similares, no se limita a la mera identificación figurativa con referentes filosóficos anteriores, sino que coloca al monarca al final de un proceso formativo que tiene como resultado la adquisición del grado de filósofo. Al hacerlo, recoge la idea de Platón:

"A menos que los filósofos reinen en los Estados, o los que ahora son llamados

reyes y gobernantes filosofen de modo genuino y adecuado, y que coincidan en una misma persona el poder político y la filosofia, y que se prohíba rigurosamente que marchen separadamente por cada uno de estos dos caminos las múltiples naturalezas que actualmente hacen así, no habrá, querido Glaucón, fin de los males para los Estados ni tampoco, creo, para el género humano." (Platón 1988: 282)

Para Platón no tendrán fin los males de los hombres hasta que los filósofos gobiernen los Estados, o hasta que los gobernantes se conviertan en filósofos. Con su propuesta arquitectónica, Friedrich Gilly crea un mecanismo capaz de transformar al gobernante en filósofo. El proyecto de Gilly es revolucionario porque reconoce la importancia de la educación frente a las cuestiones de origen: Federico no ha alcanzado el elevado estatus en que se encuentra gracias a su aristocrática cuna, sino en virtud de un proceso formativo que, al haber sido identificado y materializado por Gilly en un modelo concreto, puede hacerse extensivo al resto de la humanidad. Por lo tanto, la propuesta de Gilly para albergar la imagen del monarca es, ante todo, un edificio educativo.

Para desarrollar el programa pedagógico asociado al monumento, Friedrich Gilly recurre a la teoría del conocimiento de Kant. Éste divide la filosofia en dos grandes ramas: la filosofia de la naturaleza y la filosofia de la moral, que se corresponden con la esfera de la naturaleza y la esfera de la libertad respectivamente (Kant 2001: 95- 96), es decir, con el mundus sensibilis y el mundus intelligibilis, los dos hemisferios del globus intellectualis (Paulsen 1902: 110). El primero se rige por leyes físicas, y está sujeto a coordenadas espaciotemporales. El segundo, sin embargo, existe sin más; no participa de las intuiciones a priori del tiempo y el espacio, porque no se aloja en el mundo terrenal de los hombres, sino en el mundo trascendental de los seres puramente racionales.

Friedrich Gilly relaciona estos dos ámbitos, el de la naturaleza y el de la moral, con los dos ejes en que ha dividido el edificio que, en el proyecto definitivo, han sido redefinidos respecto a la propuesta previa. El eje longitudinal corresponde ahora al enterramiento; éste se determina mediante un movimiento que se mantiene vinculado al plano del suelo y conecta la portada de acceso con la Leipziger Strasse, es decir, con el bullicio de la ciudad, atravesando en su fluir la gruta en la que se encuentra el sarcófago del monarca. Este eje remite a la esfera de la naturaleza; en él se recoge la 

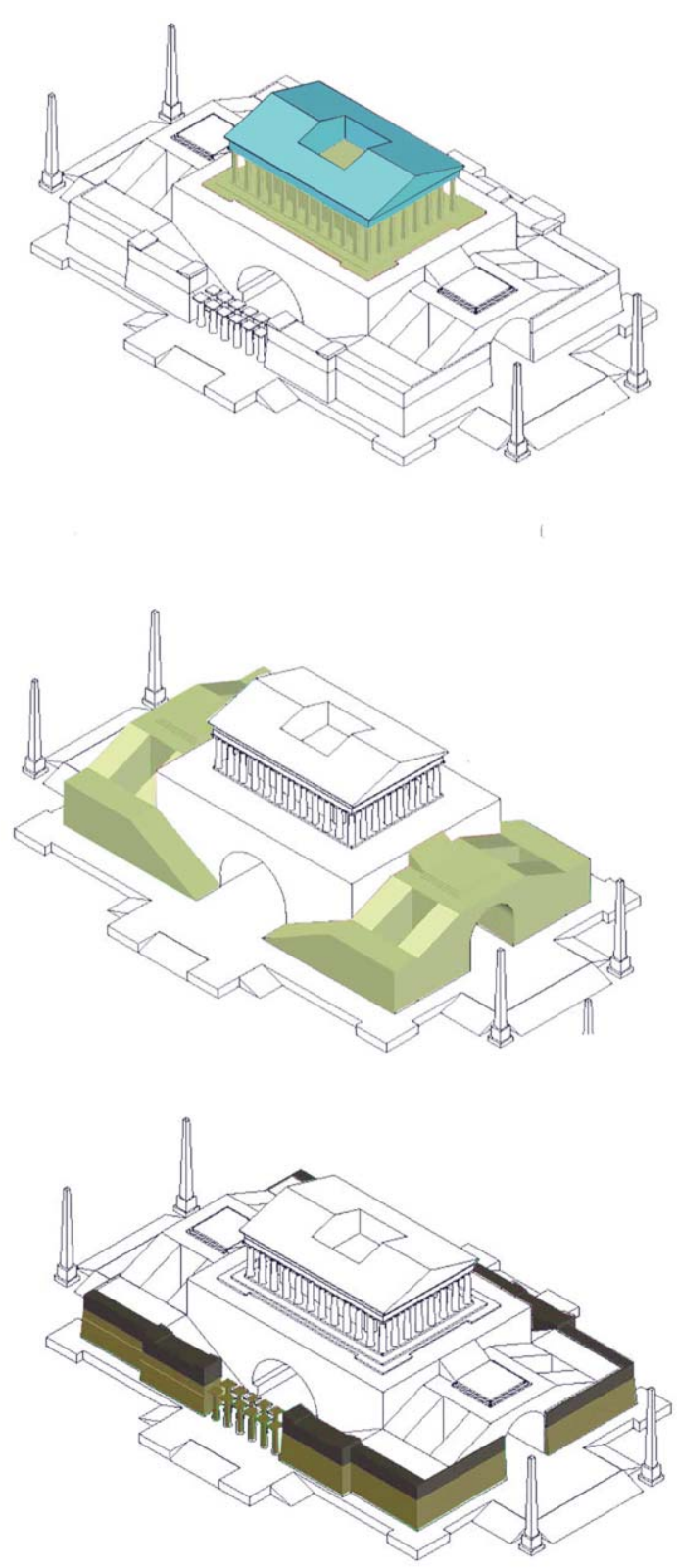

Figura 34. Determinación de las fases en el proceso de ascenso al templo. Esquema de la autora.

Figura 35: Sección longitudinal de la propuesta de Friedrich Gilly para el monumento a Federico II de 1797 (Von Simson 1975: página sin especificar). zas vivas de la ciudad. mentos alineados (figura 32): la portada de acceso y los dos volúmenes en cuya parte superior se han tallado las escaleras de ascenso al templo.

En ellos se han perforado arcos similares, convertidos, por la condición masiva de los bloques, en sendas bóvedas de cañón que parecen ser la huella de un movimiento que atravesara todo el conjunto (figura 33).

El eje transversal corresponde al monumento representativo; éste se estructura mediante un movimiento ascendente que conduce desde la base del edificio hasta el nivel en que se apoya el templo, concebido a su vez como residencia de la ley moral, o ley natural del mundus intelligibilis.

La ley moral no tiene su origen en la vida, sino que está suspendida sobre ella, en forma de norma para emitir juicios sobre la voluntad, por lo que es puramente una ley lógica de acción (Paulsen 1902: 302); no se encuentra en el mundo sensible, pero los sujetos sobre los que opera- es decir, los hombres- sí lo están. La ley moral determina, por lo tanto, un recorrido por la parte racional del individuo, permitiendo el paso de éste, del mundo sensible en que se halla, al mundo inteligible. El único instrumento con el que cuenta el hombre a lo largo del proceso es su voluntad, que ejercita de un modo libre, en tanto que ser autónomo.

El recorrido de ascenso hasta el mundo moral se desarrolla en tres fases, que quedan recogidas en el monumento de Friedrich Gilly de la siguiente forma: la primera, representada en el muro perimetral, oscuro y rugoso, hace referencia a lo sensible; la segunda, asociada a las escaleras de ascenso, remite a la voluntad; y la tercera, escenificada en el templo, pulido y brillante, a lo puramente racional (figura 34).

imagen fisica del monarca, representada en su propio cuerpo carnal- aunque en sentido figurado, puesto que se trata de un cenotafio-, a la vez que enlaza con las fuer-

La circulación en torno a este eje se define mediante una analogía que asocia tres ele-
En la cúspide de la pirámide formada por estos dos sistemas, el asociado a la naturaleza y el referido a la moral, Friedrich Gilly sitúa a Federico, el legislador, el filósofo, en tanto que único ser capaz de 
administrar racionalmente la totalidad del conocimiento científico (figura 35).

Con su propuesta para el monumento a Federico II, Friedrich Gilly plantea un recorrido que convierte a los hombres en seres racionales según la teoria del conocimiento de Immanuel Kant, al permitirles alcanzar la cima de su pensamiento; con ello, materializa la filosofia kantiana en un modelo concreto, del que hace partícipe al monarca ilustrado, pero cuya fórmula puede hacerse extensiva al resto de la humanidad y al hacerlo, no solo apuesta por la formación como medio de regeneración, sino que transforma el propio pensamiento en arquitectura.

\section{Notas}

1. 1755 es el año en que Marc- Antoine Laugier publica la segunda edición del Essai sur l'Architectur, reconociendo la autoría del mismo. La primera edición vio la luz de forma anónima en 1753.

2. La Puerta de Brandemburgo, construida entre 1788 y 1791 y llamada a ser la construcción urbana más representativa de la ciudad es, de hecho, una recreación de los propíleos de la acrópolis de Atenas. La obra se desarrolló siguiendo estrictas indicaciones de Federico Guillermo II, lo que obligó a Langhans a recurrir al método de la forma sobrante, para no convertir la obra en una mera copia del monumento ateniense, como indica Schmitz (1914, p. 32).

3. El ejército de Federico II fue el más célebre del siglo XVIII (Desperta Ferro 2016); a la muerte del monarca, éste contaba con cincuenta y cinco regimientos de infanteria, doce de guarnición, trece de coraceros, doce de dragones y diez de húsares, además de artillería y otras tropas especiales, cada una con su propio uniforme. La vestimenta fue, de hecho, la gran seña de identificación del ejército prusiano, constituyendo hasta 1840 la mayor partida presupuestaria del mismo, después de la soldada. La confección de los uniformes revertía en la economía nacional, lo que contribuyó a convertir la vestimenta del ejército en una de las grandes señas de identidad nacional. Además, como afirma Daniel Hohrath (Desperta Ferro 2016: 40-41), los uniformes tenían una vida más allá del ámbito militar, puesto que los soldados, después de tres años, podian venderlos- sin botones ni adornos-, de modo que la casaca azul, muy parecida al atuendo nacional del campesino prusiano, se implantó como vestimenta habitual en los ámbitos señoriales prusianos.

4. Las figuras 8 y 9 corresponden a la imagen especular de las propuestas enviadas a concurso por Nüssle y Hillner respectivamente; en los originales, es el brazo derecho el que levanta el monarca en ambos casos.

5. Academia de artes figurativas.

6. Como indica Cord Friedrich Berghahn (2012: 377), Mendelssohn ostentaba el cargo de amanuense en Königsberg, posición que le habria permitido acceder al original de la Crítica de la razón práctica de Immanuel Kant, incluso antes de que el escrito fuese publicado. Mendelssohn habría compartido la información con su amigo Friedrich Gentz, quien, a su vez, trasladaria el pensamiento kantiano a conversaciones con su hermano Heinrich y, poste- riormente, con su joven cuñado, Friedrich Gilly.

7. Crítica del juicio

8. Theorie der Schönen Künste und Altertumswissenschaften

9. Sociedad privada de jóvenes arquitectos. Ver Schütz 1994.

10. La Casa de la Moneda fue proyectado por Heinrich Gentz y construido entre 1798 y 1800. Las obras estuvieron bajo la supervisión de David Gilly, padre de Friedrich, quien a su vez contribuyó diseñando el friso corrido que rodeaba el edificio y cuya ejecución corrió a cargo de Schadow. Se especula sobre la posibilidad de que Friedrich Gilly hubiese colaborado también en el diseño de las plantas del edificio, pero este aspecto no ha podido ser demostrado.

\section{Bibliografia}

ARENHÖVEL, Willmuth. 1979. Berlin und die Antike. Architektur, Kunstgewerbe, Malerei, Skulptur, Theater und Wissenschaft vom 16. Jahrhundert bis Heute. (Exposición celebrada en Berlin, Deutsches Archäologisches Institut del 22-IV-1979 al 22-VII-1979). Berlin: Wasmuth.

BeHr, Adalbert. 1990. Grosse Baumeister. Berlin: Henschelverlag.

Berghahn, Cord- Friedrich. 2012. Das Wagnis der Autonomie. Studien zu Karl Philipp Moritz, Wilhelm von Humboldt, Heinrich Gentz, Freidrich Gilly und Ludwig Tieck. Heidelberg: Universitätsverlag.

BlAUERT, Elke y Wippermann, Katharina. 2007. Neue Baukunst. Berlin um 1800. Berlin: Nicolai.

CASsirer, Ernst. 2007. Rousseau, Kant, Goethe. Filosofia y cultura en la Europa del siglo de las luces. Madrid: Fondo de Cultura Económica de España.

Claramonte, Jordi. 2006. Autonomía artística desde la Ilustración (Tesis doctoral). Universidad Nacional de Educación a Distancia, Madrid.

De Valera, Cipriano. 1863. La Santa Biblia, que contiene los sagrados libros del Antiguo y Nuevo Testamento. Antigua versión de Cipiano de Valera, cotejada con diversas traducciones, y revisada con arreglo á los originales hebréo y griego. Oxford: Imprenta de la Universidad.

DoebBer, Adolph. 1916. Heinrich Gentz ein berliner Baumeister um 1800. Berlin: Carl Heymann.

FEndt, Astrid, Sedlarz, Claudia y Zimmer, Jürgen. 2014. Aloys Hirt in Berlin. Weimar: Klassik Stiftung.

GILLY, Friedrrich. 1994. Friedrich Gilly. Essays on Architecture. 1796-1799. Santa Mónica: The Getty Center for the History of Art and the Humanities.

Hohrath, Daniel. 2016. Evolución y significado del uniforme prusiano. Desperta Ferro: Historia moderna, 24: 40-47.

Kant, Immanuel. 2001. Crítica del juicio. (ed. original 1790). Madrid: Espasa.

Menze, Clemens. 1975. Die Bildungsreform Wilhelm von Humboldts. Berlin: Hermann Schroedel Verlag.

Moritz, Karl Philipp. 1788. Bildende Nachahmung des Schönen. Braunschweig: Schul.

NiEMEYER, Wilhelm. 1912. Friedrich Gilly, Friedrich Schinkel und der Formbegriff des deutschen Klassizismus in der Baukunst. Mitteilungen des Kunstgewerbevereins zu Hamburg, octubre: $1-7$.

OnCKEn, Alste. 1981. Friedrich Gilly, 1772- 1800. Berlin: Mann.

PAulsen, Friedrich. 1902. Immanuel Kant. His Life and Doctrine. Nueva York: Charles Scribner's Sons.

PhilipP, Karl Jan. 1997. Um 1800. Architekturtheorie 
und Architekturkritik in Deutschland zwischen 1790 und 1810. Stuttgart y Londres: Axel Menges.

Platón. 1988. Diálogos. IV. República. (c.380 aC). Madrid: Gredos.

Ramírez, Juan Antonio, Corboz, André, Taylor, René, van Pelt, Robert y Martínez Ripol, Antonio. 1994. Dios arquitecto. Madrid: Siruela.

RIETDORF, Alfred. 1940. Gilly. Wiedergeburt der Architektur. Berlin: Hans von Hugo Verlag.

Rodríguez Adrados, Francisco. 2003. Sócrates. En: Aula Abierta: Los grandes creadores de la Literatura. Fundación Juan March, Madrid.

RÜHLE, Volker. 1997. En los laberintos del autoconocimiento: el Sturm und Drang y la Ilustración alemana. Madrid: Akal.

Schmitz, Hermann. 1914. Berliner Baumeister vom Ausgang des 18. Jahrhunderts. Berlin: Verlag für Kunstwissenschaft.

SchÜTZ, Brigitte. 1984. Friedrich Gilly 1772- 1800 und die Privatgesellschaft junger Architekten. (Exposición celebrada en Berlín, Berlin Museum, del 21-IX-1984 al 4-X-1984). Berlin Verlag Willmuth Arenhövel.

STUART, James y Revett, Nicholas. 1825. The Antiquities of Athens. Volume the Second. Londres: Priestley and Weale.

Vitruvio, Marco. 1787. Los diez libros de Architectura de $M$. Vitruvio Polion traducidos del latin y comentados por don Joseph Ortiz y Sanz, presbitero. Madrid: Imprenta Real.

Von Simson, Jutta y Mielke, Friedrich. 1975. Das Berliner Denkmal für Friedrich II., den Grossen. Frankfurt am Main, Berlin: Verlag Ullstein.
Fecha final recepción artículos: 30/04/2017

Fecha aceptación:

23/06/2017

Artículo sometido a revisión por dos revisores independientes por el método doble ciego. 